\title{
CORPORATE CRISES IN THE DIGITAL WORLD: WHAT WENT WRONG WITH CHIPOTLE?
}

by

\author{
STEPHANIE MCGUINTY \\ Bachelor of Arts, 2012 \\ University of Ottawa \\ Ottawa, Ontario, Canada
}

The Major Research Paper is submitted

in partial fulfillment of the requirements for the degree of

Master of Digital Media

\author{
In the program of Digital Media \\ Ryerson University \\ Toronto, Ontario, Canada \\ 2016
}

(C) Stephanie McGuinty 2016 


\begin{abstract}
AUTHOR'S DECLARATION
I hereby declare that I am the sole author of this MRP. This is a true copy of the MRP, including any required final revisions.

I authorize Ryerson University to lend this MRP to other institutions or individuals for the purpose of scholarly research.

I further authorize Ryerson University to reproduce this MRP by photocopying or by other means, in total or in part, at the request of other institutions or individuals for the purpose of scholarly research.

I understand that my MRP may be made electronically available to the public.
\end{abstract}

Stephanie McGuinty 


\title{
CORPORATE CRISES IN THE DIGITAL WORLD: WHAT WENT WRONG WITH CHIPOTLE?
}

\author{
Master of Digital Media, 2016
}

Stephanie McGuinty

\section{Master of Digital Media, Ryerson University}

\begin{abstract}
The practice of crisis communication has evolved since the rise of digital technologies and social media. Defined as an unexpected and non-routine event with high levels of uncertainty, crisis management plans and strategies are essential for organizations' successes. Failure to strategically manage crises through both traditional and digital media may result in significant damages and losses. This MRP examines a recent corporate crisis - the case of Chipotle Mexican Grill during the 2015-2016 E. coli outbreak across the United-States - and looks at how the social media strategy (namely Twitter) influenced the outcome of the case. Using a combination of data analytics, company financials, and theoretical frameworks, this research brings to light the importance of measuring online data, and makes suggestions on how companies may use social media to manage various types of crises.
\end{abstract}

Keywords: crisis communication, crisis theory, crisis management, crisis strategies, image repair, social media, crisis and technology, brand equity 


\section{ACKNOWLEDGEMENTS}

The execution of this major research paper would not have been possible without the guidance of my supervisor, Dr. Joanne DiNova. Thank you for your patience and support throughout the past few months. I would also like to thank my second reader, Dr. Irene Berkowitz, who initially inspired me to pursue this area of study.

Thank you to the MDM faculty and staff, namely Sonya Taccone, Michael Carter, and Art

Blake. You have fostered a truly positive academic experience this past year.

Finally, thank you to all MDM students - for your collaboration, ideas, and helping me discover the endless possibilities in this field of study. 


\section{TABLE OF CONTENTS}

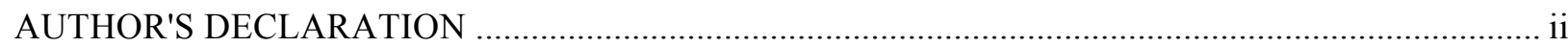

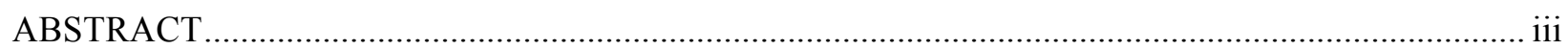

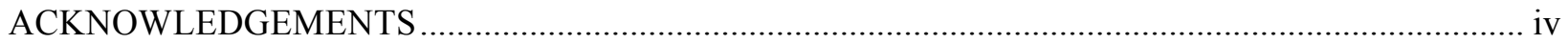

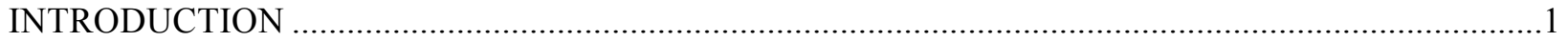

Description of Case: Chipotle Mexican Grill's E. Coli Outbreaks (United States).................................1

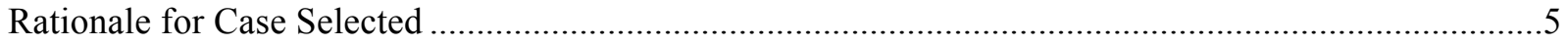

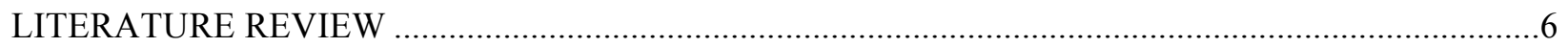

Crisis Communication vs. Risk Communication..........................................................................

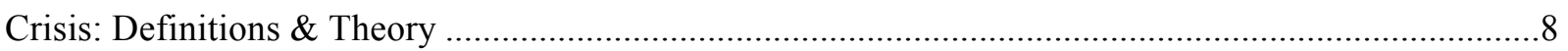

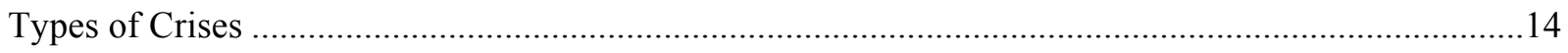

Crisis, Social Media \& Digital Communication Tools ..........................................................................16

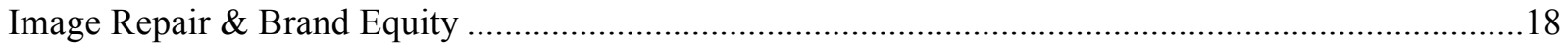

Strengths and weaknesses of studies / gaps in research...................................................................21

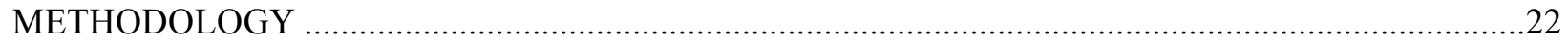

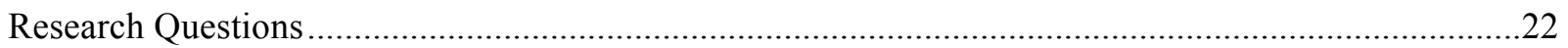

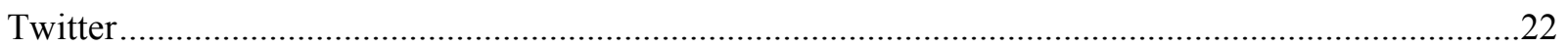

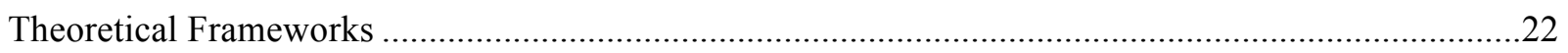

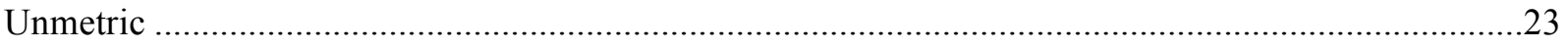

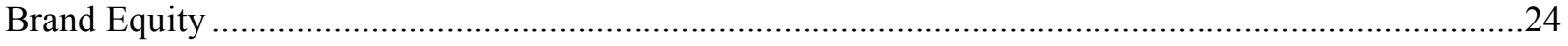

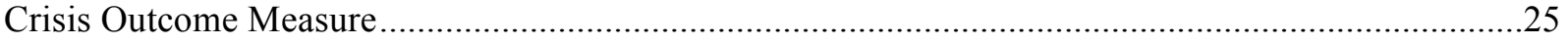

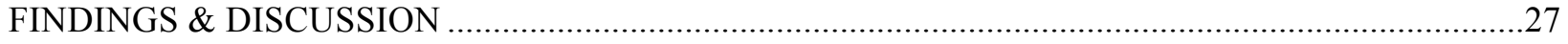

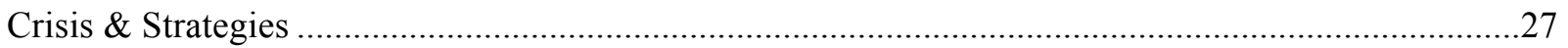

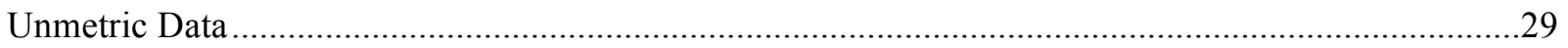

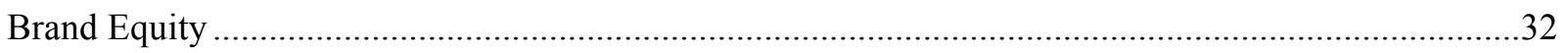

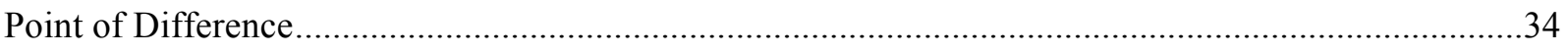

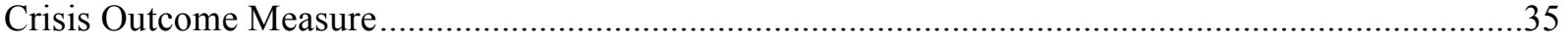

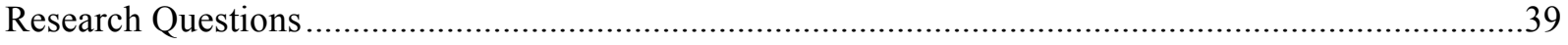

R1 - How can Unmetric analysis be deployed by managers to improve crisis management efforts?.39

R2 - How did Twitter contribute to Chipotle's handling of the crisis? .............................................43

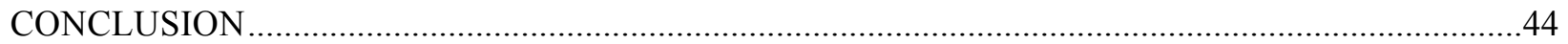

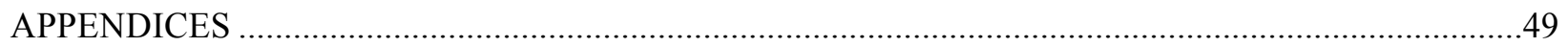

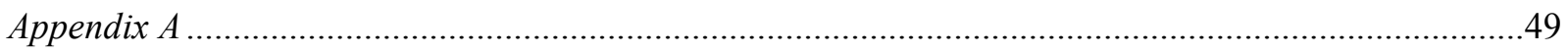


Appendix B

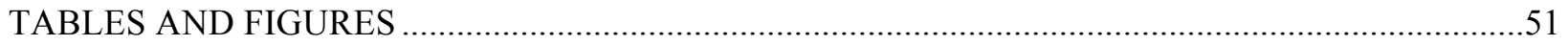

1. Pre-Crisis - Unmetric Data for period Mar 1, 2015 - Jul 31, 2015 ...........................................51

2. During Crisis - Unmetric Data for period Oct 1, 2015 - Mar 1, 2016 _......................................55

3. Post Crisis - Unmetric Data for period April 1, 2016 - Jul 8, 2016 ..........................................59

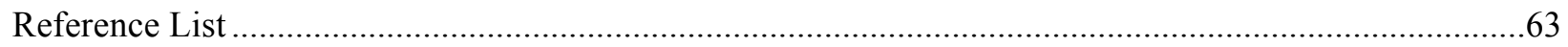




\section{INTRODUCTION}

Crises are inevitable; from natural disasters, terrorism, disease outbreaks, product failures, unethical leadership, economic downturns, and scandals, crises of all kinds continue to present challenges and opportunities for individuals, nations, and organizations. In the twentyfirst century, internet and digital media present a different level of crisis and crisis communication management challenges. Nowadays, not only must crisis communication specialists consider traditional, unidirectional methods of crisis communications, they must also consider digital strategies. The following research examines a recent crisis communication case while bringing to light the importance of social media during such times. The literature review will provide a comprehensive overview of crisis communication theory as it relates to image repair, brand equity, and social media. The methods section will outline how data has been gathered and states the rationale for using selected methods. Finally, the discussion presents findings and conclusions linked to the three main research questions. Using a combination of theoretical frameworks and data analytics, the research findings present social media strategies and discusses the use and importance of analytics during organizational crises. The following pages will provide an overview of the case, along with a rationale for why this particular case was selected.

\section{Description of Case: Chipotle Mexican Grill's E. Coli Outbreaks (United States)}

Founded in 1993 by (then) cook Steve Ells, Chipotle Mexican Grill (NYSE) is a publiclytraded, fast food restaurant chain with over 2,000 stores across North America and some countries in Europe (Chipotle Investor Relations, 2015). Chipotle is a leader in the fast food industry, competing with brands like McDonald's, Taco Bell, and Nando's. The crisis case is examined from October 1, 2015 to March 1, 2016. In October 2015, over 55 outbreaks of E. coli 
were identified in eight of Chipotle's restaurants, which led to the closure of 43 restaurants in Oregon and Washington State in early November 2015. Chipotle was quick to close its stores and provided a number of statements to news sources, in addition to its main investor relations page: "The safety and well-being of our customers is always our highest priority. After being notified by health department officials in the Seattle and Portland, Ore. areas that they were investigating approximately 20 cases of E. coli, including people who ate at eight of our restaurants in those areas, we immediately closed all of our restaurants in the area out of an abundance of caution, even though the vast majority of these restaurants have no reported problems. [...] We offer our deepest sympathies to those who have been affected by this situation” (Chipotle Investor Relations, 2015, par. 3). From October 2015 to January 2016, about five hundred cases of individuals affected with E. coli symptoms were reported (not all investigated), including 27 hospitalizations. As stated above, Chipotle's case was first reported in the news as early as October 2015, but the company did not address the issue on Twitter until November 9, 2015.

Following official investigations, restaurants were quickly re-opened late November as it was concluded there were no further risks associated with this incident. In December, Chipotle announced a new sanitization measure of its produce; it would sanitize all produce at a centralized location before shipping them to restaurants, and implement a DNA-based test for all products before restaurants received ingredients (Chipotle Investor Relations, 2015).

Unfortunately for Chipotle, sales and stock prices were heavily affected by these incidents. In the fourth quarter of 2015, Chipotle reported a decline in revenue for the first time in its history as a public company, dropping $44 \%$ in revenues and shares falling 8.6\% (Wall Street Journal, 2016). Furthermore, dozens of civil lawsuits (namely Susie Ong v Chipotle et al, U.S. District Court, 
Southern District of New York, No. 16-00141; ) were filed in various courts against Chipotle, for failure to disclose its poor quality control which was inadequate to protect consumer and employee health (Polansek in Reuters, 2016) - yet another complication for Chipotle (Associated Press, 2015).

In January 2016, a few other cases of norovirus and E. coli were identified, affecting both customers and employees of Chipotle. This caused the U.S. Food and Drug Administration (FDA) to step in and conduct official investigations on Chipotle's store operations (FDA, 2016), as this was considered a public health issue. Moreover, the Department of Justice was forced to conduct an open investigation into the company for possible criminal activity regarding the $\mathrm{E}$. coli outbreaks (Investopedia, 2016). The FDA traced back various ingredients to their origins, as well as supplier investigations, but did not find the source of outbreak; as such Chipotle resumed normal business activity. On February 1, 2016, the FDA concluded the outbreak appeared to be over. In order to address this crisis publicly, on February 8, 2016, the company closed all of its U.S. stores for a four-hour virtual organization-wide meeting regarding new food safety measures at headquarters (Denver), where over 50,000 employees tuned in via video. During this period, the company posted live tweets on Twitter and broadcasted the meeting on Periscope. As stated in an article from Bloomberg, the real problem for Chipotle is that the freshness of its food - which is the core of its brand appeal - has made it a big weakness for them: "It strikes deeper at their brand because so much of their story is based on the quality of their ingredients," stated brand consultant Allen Adamson (Bloomberg News, 2015, par. 4). Despite criticism and lingering concerns, reported cases of E. coli ceased - but unfortunately for Chipotle, this was short-lived. 
Although the crisis period examined ends on March 1, 2016, it is important to note there have been a few other cases announced on social media. Most recently on July 7, author of Jason Bourne series Eric van Lustbader tweeted about his editor being sick after having eaten at a Chipotle in New York city (Business Insider, 2016). Although it was not proven that Chipotle was at fault, company shares fell $3.4 \%$ following this tweet, perhaps illustrating the damage that had already been done in previous months (CNBC, 2016). In response to this, Chipotle spokesman Chris Arnold stated "we are aware of the post made on Twitter however there have been no reports of illnesses at any of [the] New York Restaurants. Moreover, [Chipotle] [has] excellent health department scores throughout the city, and we continue to have the highest standards of food safety in our restaurants" (Fortune Magazine, par. 4). Interestingly, this tweet appeared following the arrest of Mark Crumpacker, one of Chipotle's top executives - for possession of cocaine (Fortune Magazine, 2016). According to Bloomberg news, Crumpacker is accused of making a first cocaine purchase on January 29, 2016, a few days before the U.S. CDC released results of E. coli outbreaks.

It seems as though remains of the crisis continue to resurface - whether it be in the news or online. However, Chipotle has expressed optimism in bringing the company back to its normal state. In late April 2016, the executive team announced they would expand their menus, develop a loyalty program, and spend more on advertising (Fortune Magazine, 2016). The company also understands losses have stopped them from opening new stores, said co-Chief Executive Monty Moran: "After adding about 200 restaurants annually in recent years, Chipotle is now carefully reviewing new restaurant projects it had previously green-lighted" (Fortune Magazine, 2016, par. 6). Results in the second quarter in 2016 showed that Chipotle's profits were down $82 \%$ compared to summer 2015 (CNN, 2016). Finally, as a result of these incidents, executives did 
not receive bonuses to compensate for plummeting sales in the last quarter of 2015 and first quarter of 2016 (Chipotle Investor Relations, 2016). Whether or not this will help the company regain traction - or just a simple public-relations tactic - has yet to be determined.

\section{Rationale for Case Selected}

This case was selected as Chipotle is one of the largest, and most prominent fast-food restaurants in the United-States. It also has a large following on social media, and is known to post frequent content and actively engage on social media with its customers. Today, Chipotle has approximately 785,000 Twitter followers, $(743,000$ at the time of crisis) and over 2 million Facebook page likes. The company also actively uses Facebook, YouTube, Instagram, Pinterest, and LinkedIn as social platforms (Unmetric Data, 2016). Without a large following on social media, the methodology and research outcomes would differ greatly, as there would not be enough data to provide informed recommendations for crisis managers. It was important to select a case that would allow for substantive data gathering in order to better address the research question and conduct a thorough data analysis. As outlined in the data section of this paper, there are over 40,000 tweets posted on behalf of the company and users during the crisis period examined. According to 2016 Unmetric data analytics, Chipotle ranks seventh in Twitter following in the food \& beverage sector (following Starbucks, McDonald's, Taco Bell, Nando's, Pizza Hut, and Domino’s Pizza).

Secondly, this case took place in the United States and is recent in nature - technically the case was active from October 1, 2015, to February 8, 2016, although it is debatable whether or not this case has officially closed. By selecting a case that took place within the last year, information is more relevant and findings from the analysis will provide better suggestions for future crisis managers. 
The case overview has provided a context for understanding this research and field of study. In the following section, crisis communication theory will be discussed to provide a better understanding of the concepts and definitions used in the remaining parts of this paper. The methodology section will outline the variables and rationale for selected measures and tools. Finally, the findings section will discuss results as they relate to the research questions, and provide recommendations for future research.

\section{LITERATURE REVIEW}

Crisis communication theories have been researched in-depth since the early 1980s. Contributions to the research include analysis of theoretical disciplines from psychology, management, political science, and socio-economic perspectives. Crisis communication definitions and theories are diverse, as they can be examined from different disciplines and touch on different theories. In the past few years, researchers have developed theoretical approaches for responding to organizational crises (Ulmer, Sellnow \& Seeger, 2015; Coombs, 2007; Reynolds and Seeger, 2005). Some classic theories include Benoit's (1997) Image Repair Theory and Coombs' Situational Crisis Communication Theory (1995), which will be further examined in this literature review. Most recently, studies have focused on empirically-tested crisis case strategies, allowing for better applicability and understanding of crisis management. In fact, recent studies show an increased interest and need for crisis management as a result of digital technology malfunctions, which is a testament to many consulting firms now offering crisis management services, such as Deloitte, Edelman, and FleishmanHillard. Alternatively, technology can be used as a catalyst for exploiting crises or as a tool to manage them. This paper will look at Twitter, and how it can be used to strategically manage crises based on the analysis of Chipotle's E. coli outbreak, a nation-wide organizational crisis. The following literature 
review will address past and current research from the perspective of various academics and scholars. The goal is to obtain a better understanding of crisis communication, crisis strategies, and crises in the digital age. Literature is drawn from various research, publications and authors, as well as agencies specializing in public relations and crisis communication management.

\section{Crisis Communication vs. Risk Communication}

It is important to distinguish between crisis and risk communication, as they are sometimes used interchangeably in literature. Risk communication, at its basic form, is the communication of some risk. The purpose of risk communication may differ based on the situation - for example, alerting food workers to a potential disease breakout, or informing customers about a defective product that may harm them. In a 1989 publication, the National Research Council (NRC) defined risk communication as "an interactive process of exchange of information and opinion among individuals, groups, and institutions” (NRC, 1989, p.2).

Reynolds and Seeger (2005) define risk as a process informing people about risks, and persuading them to modify their behaviours to reduce risk. The authors provide a distinction between risk and crisis which help understand the separation, as seen in Table 1.

Table 1

Differences Between Risk and Crisis

\begin{tabular}{l|l}
\hline Risk & Crisis \\
\hline Future oriented & Specific incident \\
Messages of reducing likelihood & Messages of blame and consequences \\
Based on what is currently known & Based on the known and unknown \\
Long term & Short term \\
Technical experts, scientists & Authoritative figures \\
Personal scope & Community perspective \\
\hline
\end{tabular}




\begin{tabular}{l|l}
\hline Mediated communication campaigns & $\begin{array}{l}\text { Press conferences, press releases and } \\
\text { speeches } \\
\text { Spontaneous and reactive }\end{array}$ \\
\hline
\end{tabular}

Table 1. Differences Between Risk and Crisis. Adapted from "Crisis and Emergency Risk Communication as an Integrative Model", by Reynolds and Seeger, 2005, Journal of health communication, 10(1), p.48. Copyright 2005 by Taylor \& Francis Inc.

Additionally, Lundgren \& McMakin (2013) identify three different types of risks: care communication, safety communication, and health communication. What links these risks together are the types of communication methods, which include care communication, consensus communication, and crisis communication. In this case, crisis communication is defined as "risk communication in the face of extreme, sudden danger [...]. This type can include communication both during and after the emergency" (Lundgren \& McMakin, 2013, pp. 4-5). The authors certainly view risk and crisis communication to be interdependent, falling under the same scope of communication strategy. Other authors view crisis as a broader concept, such as Heath \& O’Hair (2009), who define crises as a more niche discipline related to any event affecting an organization or individual. The authors recognize that risk and crisis are interrelated concepts which organizations must be prepared for at all times.

While there may be some overlap in definitions, this paper will separate risk from crisis, much like views posited by Ulmer, Sellnow \& Seeger (2015), who believe that "while risk is a natural part of life, crisis can often be avoided. [...] Crisis and risk are closely connected, as poor risk communication can cause a crisis" (p.10). This statement applies to the case examined in the research, as Chipotle's case is both crisis and risk-related.

\section{Crisis: Definitions \& Theory}

A prominent researcher in the field of crisis communication is Coombs, whose definition of crisis is "the perception of an unpredictable event that threatens important expectancies of 
stakeholders and can seriously impact an organization's performance and generate negative outcomes" (Coombs, 2007, p. 2-3). In order to guide organizational responses to crises, Coombs developed the Situational Crisis Communication Theory (SCCT), a framework developed for understanding how to protect an organization's reputation following a crisis. The SCCT framework consists of six elements, namely the crisis cluster, crisis response strategies, crisis history, prior reputational threat, organizational reputation, and behavioural intentions. The SCCT framework is shown in Appendix A.

Drawing from experimental methods and socio-psychological theory, SCCT identifies how key elements of a crisis situation influences perceptions about the crisis and the reputations held by stakeholders. In turn, understanding how stakeholders will respond to the crisis helps determine the post-crisis communication (Coombs, 2007). Coombs believes that adopting strategic responses may help organizations achieve crisis management goals, like lowering negative reputation remarks and minimizing economic losses. SCCT draws from Attribution Theory, which suggests that people often search for causes of events, especially in negative times (Weiner, 1985).

Based on SCCT, Coombs (2007) devises crisis response strategies used to repair reputations of organizations, which consist of the following four strategies: denying, diminishing, rebuilding, and bolstering (Table 2). As response strategies become more accommodative and show more concern for victims, the involved stakeholders perceive the organization as taking greater responsibility for the crisis (Coombs \& Holladay, 2011). These strategies have three objectives in relation to protecting reputations: (1) shape attributions of the crisis; (2) change perceptions of the organization in the crisis, and; (3) reduce the negative affect generated by the crisis (Coombs, 1995). Coombs identifies some limitations of these strategies, 
explaining that without financial resources, it may be difficult for organizations to select the best and most appropriate strategy. Another limitation includes media framing, which is difficult to overturn, as many studies show that stakeholders hold the same perceptions as the media's agenda (Coombs, 2007: Reese, Westphal. \& Carroll, 2004).

\section{Table 2}

\section{SCCT Crisis Response Strategies}

\begin{tabular}{|c|c|}
\hline $\begin{array}{l}\text { Primary crisis } \\
\text { response strategies }\end{array}$ & $\begin{array}{l}\text { (1) Deny crisis response strategy } \\
\text { - Attack the accuser: Crisis manager confronts the person or group claiming } \\
\text { something is wrong with the organization } \\
\text { - Denial: Crisis manager asserts that there is no crisis } \\
\text { - Scapegoat: Crisis manager blames some person or group outside of the } \\
\text { organization for the crisis } \\
\text { (2) Diminish crisis response strategies } \\
\text { - Excuse: Crisis manager minimizes organizational responsibility by denying } \\
\text { intent to do harm and/or claiming inability to control the events that triggered the } \\
\text { crisis } \\
\text { - Justification: Crisis manager minimizes the perceived damage caused by the } \\
\text { crisis } \\
\text { (3) Rebuild crisis response strategies } \\
\text { - Compensation: Crisis manager offers money or other gifts to victims } \\
\text { - Apology: Crisis manager indicates the organization takes full responsibility for } \\
\text { the crisis and asks stakeholders for forgiveness }\end{array}$ \\
\hline $\begin{array}{l}\text { Secondary crisis } \\
\text { response strategies }\end{array}$ & $\begin{array}{l}\text { (4) Bolstering crisis response strategies } \\
\text { - Reminder: Tell stakeholders about the past good works of the organization } \\
\text { - Ingratiation: Crisis manager praises stakeholders and/or reminds them of past } \\
\text { good works by the organization } \\
\text { - Victimage: Crisis managers remind stakeholders that the organization is a } \\
\text { victim of the crisis too }\end{array}$ \\
\hline
\end{tabular}

Table 2. SCCT Crisis Response Strategies. Adapted from "Protecting Organization Reputations During a Crisis: The Development and Application of Situational Crisis Communication Theory", by T. Coombs, 2007, Corporate Reputation Review, 10(3), p.170. Copyright 2007 by Palgrave Macmillan Ltd.

In order to determine the best crisis strategy, Coombs (2011) recommends that organizations use the SCCT model by identifying type of crisis (victim, accidental, or 
preventable) (Table 3) and then selecting the most appropriate response strategy based on Table

2. In the victim cluster, the organization is seen as a victim of the event, such as natural disasters.

In the accidental cluster, the event is seen as unintentional, such as equipment failure which causes a product to be recalled. In the third cluster, the preventable cluster, there are strong attributions of a crisis responsibility and blame is pointed at the accused, such as laws violated by a management team.

Table 3

Coombs' Situational Crisis Communication Theory (SCCT) - Types of Crises

\begin{tabular}{l|l|l}
\hline Cluster & Type & Example \\
\hline Victim & $\begin{array}{l}\text { Natural Disaster } \\
\text { Rumour } \\
\text { Hacking } \\
\text { Workplace Violence }\end{array}$ & $\begin{array}{l}\text { Natural disaster } \\
\text { False rumour about a company } \\
\text { Cyberhacking } \\
\text { Employee harms other employee }\end{array}$ \\
Accidental & $\begin{array}{l}\text { Challenges } \\
\text { Technical errors products } \\
\text { Technical errors accidents }\end{array}$ & $\begin{array}{l}\text { Technology failure } \\
\text { Technology failure causes accident }\end{array}$ \\
& Human error accident & Human error causes accident \\
Preventable & Human error product harm & $\begin{array}{l}\text { Human error causes harmful product } \\
\text { Oeaders of company make wrong ethical } \\
\text { decisions }\end{array}$ \\
\hline
\end{tabular}

Table 3. SCCT Crisis Types. Adapted from "Protecting Organization Reputations During a Crisis: The Development and Application of Situational Crisis Communication Theory", by T. Coombs, 2007, Corporate Reputation Review, 10(3), p.168. Copyright 2007 by Palgrave Macmillan Ltd.

Another prominent researcher in the field is Robert Ulmer, whose work focuses on the opportunities in crisis communications. In the book Effective Crisis Communication (2013), Ulmer, Sellnow \& Seeger discuss five disciplines in relation to crises, all of which have contributed to understanding crises: psychology, sociology, business, mathematics and physics, and political science. Each academic discipline contains a set of theories, such as psychology, 
which allows for a better understanding of mental model approaches to crisis communication and helps understand how individuals perceive and respond to crisis situations. Alternatively, the field of business touches on organizational sense-making theory (Ulmer, Sellnow \& Seeger, 2013). The authors also define three media theories that should be considered in the lifecycle of a crisis. The first media theory is news framing - that is, the media may frame the crisis positively or negatively, affecting the public opinion. The second is focusing on events, which simply refers to reporting policy decision made in response to crisis events and discussing likelihood of reoccurrence. Third is news diffusion, whereby the company works with the media, who then distributes information quickly and accurately through various channels.

Many researchers have approached crises from an organizational perspective. One of the early researchers in organizational crisis management is Charles Hermann, who defines organizational crises as "situations unanticipated by the organization" (Hermann, 1963, p. 81) and are defined by the following three elements: they present a threat to organizational values, there is a restricted amount of time for response, and they are unexpected by organizations (Hermann, 1963). Hermann states that interest in the study of organizational crisis stems from international crises, and how such events can affect both society and the organization itself. An organizational crisis differs from other types of crises because of its relationship to an entity, corporation, employer, government, or organized group.

In the 1990s, similar definitions of organizational crisis emerged. Pauchant \& Mitroff defined it as "a disruption that physically affects a system as a whole and threatens its basic assumptions, its subjective sense of self, its existential core” (Pauchant \& Mitroff 1992, p.12). Similarly, Fearn-Banks defined a crisis as "a major occurrence with a potentially negative outcome affecting an organization, company, industry, as well as its publics, products, services, 
or good name" (Fearn-Banks, 1996, p.1). As noted in a paper by Jacobsen and Simonsen (2011), these definitions indeed address the effects within an organization, but do not discuss how the crisis emerged (Jacobsen \& Simonsen, 2011, p.3). This represents somewhat of a limitation of these definitions; however other literature addresses these gaps.

A more recent definition by Ulmer, Sellnow \& Seeger (2015), states that an organizational crisis "is a specific, unexpected, and nonroutine event [...] that create[s] high levels of uncertainty and simultaneously present an organization with both opportunities for and threats to its high priority goals." (p.8, italics in original). Furthermore, organizational crises are "unique moments in the history of organizations" which are usually caused by leadership mistakes or other oversights (Ulmer, Sellnow, \& Seeger, 2015, p.6).

As this research examines a recent crisis case, it is important to examine modern research practices and theory. A unique perspective to crisis communication appears in the study of human behaviour and information and communication technology (ICT). ConnectivIT Lab, a research group at the University of Colorado, focuses on crisis informatics, which is the study of technical, social, and information aspects of crises. Led by Leysia Palen, the group hopes that looking at various angles will result in effective technology design and policy development for crisis communicators (Palen, 2008). The group examined the case of Virginia Tech shootings (2007), where affected students posted information on blogs and user-generated websites to identify victims. Although many turned to national news, internet activity drove substantial traffic to websites like Wikipedia and Facebook. This illustrates the power and importance of user-generated content in times of crises before the affected institution was even able to do so. 


\section{Types of Crises}

Organizational crises are at the centre of this paper, but these types of crises certainly vary by type and nature. Meyers and Holusha (1987) list nine types of crises for which all organizations must be prepared for: public perception, sudden market shifts, product failures, top management succession, cash crises, industrial relations, hostile takeovers, adverse international events, regulation/deregulation. Table 4 illustrates examples of crisis type:

\section{Table 4}

\section{Meyers \& Holusha's (1986) Nine Types of Crises with Examples}

\begin{tabular}{l|l}
\hline Crisis Type & Example \\
\hline Public Perception & $\begin{array}{l}\text { Negative perception may reduce sales of products and tarnish } \\
\text { reputation; usually enhanced by media coverage }\end{array}$ \\
Sudden Market Shifts & $\begin{array}{l}\text { Change in consumer preferences, such as electronic devices } \\
\text { (iPhone versus Blackberry) } \\
\text { Automobile deficiencies may result in passenger deaths or } \\
\text { accidents } \\
\text { Product Failures }\end{array}$ \\
$\begin{array}{l}\text { Top Management } \\
\text { Succession }\end{array}$ & $\begin{array}{l}\text { Cash problems may represent other organization problems, such } \\
\text { as the Enron crisis in 2001 }\end{array}$ \\
Industrial Relations & $\begin{array}{l}\text { Strikes may result in service slow downs or temporary shut- } \\
\text { downs } \\
\text { Low }\end{array}$ \\
Adverse International Events & $\begin{array}{l}\text { The Gulf War impacted various industries, especially in the oil } \\
\text { sector } \\
\text { Changes in the operational environment }\end{array}$ \\
\hline
\end{tabular}

Table 4. Nine Types of Crises. Retrieved from When it hits the fan: Managing the nine crises of business, by G.C. Meyers \& J. Holusha, 1986, Boston, MA: Houghton Mifflin. Copyright 1986 by Reed Business Information Inc.

Crises can be intentional, such as terrorism and unethical leadership, or unintentional, such as natural disasters and product failures (Ulmer, Sellnow \& Seeger, 2015). This research 
will address both types. An example of risk communication case would be earthquakes and floods, which are incidents that affect organizations rather differently than unethical management, for example. Examples of intentional crises are the 9/11 terrorist attacks in New York or the 2001 Enron scandal, and unintentional crises would be the 2008 economic downturn, where the United-States, among many countries, experienced one of the worst financial downturns since the Great Depression (Ulmer et. al, 2015).

Another, more recent type of crisis involves technology. Technology can certainly be the cause of a crisis, such as the recent Ashley Madison cyber-hack in 2015, where names of more than 36 million users looking to engage in romantic or sexual encounters - while being in committed marriages or relationships - were leaked to the public as a result of a cyber attack. This raised an interesting issue, both on crisis management for the company, as well as risk communication in protecting the names of users. As humans become more dependent on technology, exposure to crises increases, and understanding how to manage these crises is an important skill (Ulmer, Sellnow \& Seeger, 2015). Moreover, technology can be used as an important tool to inform about risks and crises, such as Facebook's "Safety Check" function, which came into effect following the 2015 Nepal earthquake. Facebook launched this feature following the tsunami in Japan after noticing a high volume of social media use by users to stay connected with one another. Following the events, Facebook CEO Mark Zuckerberg stated that "when disasters happen, people need to know their loved ones are safe [...] It's moments like this that being able to connect really matters" (Zuckerberg's Facebook page, 2015).

Finally, technology and social media can become powerful tools to overcome crises and manage a brand's reputation, as they allow communication with a large audience and allow for interaction between company and user. Many professional athletes have used social media to 
manage their personal brands. In 2014, NFL player Greg Jennings hosted a contest on Twitter to win a pair of his gloves following his 500th reception. After about 30 minutes, this tweet became one of the most popular topics in the United States and generated traffic to his Twitter account, fostering interaction among fans and thus drawing more attention to the athlete. Due the significance of social media analysis to this study, this topic will be addressed in great detail in the next section. Furthermore, the relationship between crises, social media, and brand reputation will be explored more in-depth in the research portion.

\section{Crisis, Social Media \& Digital Communication Tools}

Theoretical approaches to crises have been discussed in previous parts of this paper as they are prominent in literature. Many researchers have focused on crisis theory rather than applied and empirically-tested crisis cases and solutions (Coombs, 2007). The Organization for Economic Co-operation and Development (OECD) suggests the importance of crisis management and how social media can represent both challenges and opportunities for crisis managers. The authors discuss the evolving context for risk and crisis communication strategies, which is closely related to the emergence of social media and technological innovation, similar to the case of Virginia Tech in the United States:

In many countries public expectations and roles are changing in terms of the desire for increased transparency of information, in the spirit of open government, and participation in information gathering, sharing and verification. The trust in established experts, public officials and numerous bloggers has changed. The public is no longer content to receive official recommendations and advice in a passive way. People are gradually shifting from a situation where the information was pushed on them and made available by authorities, to a situation where the information can also be pulled $[\ldots]$. Social media have also created new arenas of information exchange where dynamic and interactive flows of data are in the hands of millions of individuals, who seek a more 
evidence-based participatory form of risk and crisis communication"(Wendling, Radisch \& Jacobzone, 2013, p.10).

With the increased use of technology and social platforms, it is imperative that organizations devise crisis management strategies - not only traditional ones, but using social media as well. It is important to differentiate social media from digital media: social media are platforms where users can share information and form relationships, such as Facebook, Twitter, and online Blogs, whereas digital media are communication technologies with features that facilitate interaction among users, such as mobile devices, apps, and the internet (Valentini \& Kruckerberg, 2012). For the purpose of this paper, the focus will be Twitter due to its ability to reach a larger amount of users, as opposed to digital media, which cannot be used as a channel to communicate with an audience.

One particular study used "Social Mention," an analytics platform that aggregates usergenerated content from social media platforms, which was used to determine the attributes of good crisis messages communicated via social media, as well as best practices for communicating via social media during crisis situations (Freberg et al., 2011). The authors determined that the following considerations take place when an organization communicates in times of crisis: use consistent hashtags across platforms - for example, during Hurricane Irene, hashtags varied by location (North Carolina used "ncirene" and Maryland used "mdirene"). Hashtags "are useful to incorporate strategically into a crisis communications plan not only for others to use in monitoring what others are saying, but to ensure that those impacted in the crisis situation are able to follow what others are reporting” (Freberg et al., 2013, p. 190). A second important tactic is to include links to sources, photos, or videos within a social media update, especially when there are character limitations, such as Twitter. Finally, a focus on safety is important, especially when there is a risk involved. These best practices will inform the research 
component of this paper and be used as guiding principles, as strategies for social media in crisis communication cases will be established following the analysis of Chipotle's case.

\section{Image Repair \& Brand Equity}

An important consideration to make in the evaluation of crisis strategies is image repair, brand reputation and brand equity. Corporate crises may damage reputations, especially if the organization does not address the crisis strategically. William Benoit's (1995) theory of image restoration, which has roots in the theory of apologia, helps understand how organizations can recover from crises. Benoit outlines two essential elements of an organization that is under reputational threat: (1) the organization or person at fault is held responsible for the crisis and (2) the crisis situation is considered offensive. He also argues that corporations have reputations that are valuable to the corporation and require protection. Benoit outlines five strategies of image restoration, listed from least to most involved, as illustrated in Table 5.

\section{Table 5}

\section{William Benoit's Image Restoration Strategies (1995)}

\begin{tabular}{l|l}
\hline Strategy & Key Characteristic \\
\hline Denial & \\
Simple Denial & Did not perform act \\
Shift the Blame & Act performed by another \\
Evasion of Responsibility & \\
Provocation & Responded to act of another \\
Defeasibility & Lack of information or ability \\
Accident & Act was a mishap \\
Good Intentions & Meant well in act \\
Reducing Offensiveness of Event & \\
Bolstering & Stress good traits \\
Minimization & Act not serious \\
Differentiation & Act less offensive \\
Transcendence & More important considerations \\
Attack Accuser & Reduce credibility of accuser
\end{tabular}




\begin{tabular}{l|l} 
Compensation & Reimburse victim \\
Corrective Action & Plan to solve or prevent problem \\
Mortification & Apologize for act
\end{tabular}

Table 5. Benoit's Image Restoration Strategies. Adapted from "Sears' repair of its auto service image: Image restoration discourse in the corporate sector" by W.L. Benoit, 1995, Communication Studies, 46(1-2), p. Copyright 1995 by JAI Press Inc.

Another measure of crisis management success and failure outcome variables, which ultimately may result in repairing or tarnishing a reputation, are identified by Pearson \& Clair (1998). As outlined in Table 6, crisis successes may vary depending on different outcome variables, such as how early the crisis was detected and contained, how the organization learned from the crisis, and the impact on the organization's reputation. This model serves as important success measures for the remaining research portion, as it provides a baseline for measurable criteria to determine the success or failure of crisis management outcomes. The difference between this model and Benoit's Image Restoration Strategies is that it provides specific concerns that can be used as variables to observe an organization's crisis management success.

\section{Table 6}

Examples of crisis management success and failure outcomes (Pearson \& Clair, 1998)

\begin{tabular}{l|l|l|l}
\hline Crisis Concern & Failure Outcomes & Midground Outcomes & Success \\
\hline Signal Detection & $\begin{array}{l}\text { Signals of crisis are } \\
\text { ignored }\end{array}$ & $\begin{array}{l}\text { Signals of crisis send } \\
\text { organization into state } \\
\text { of alertness }\end{array}$ & $\begin{array}{l}\text { Signals are detected early } \\
\text { so that appropriate } \\
\text { responses are set }\end{array}$ \\
$\begin{array}{l}\text { Incident } \\
\text { Containment }\end{array}$ & $\begin{array}{l}\text { Crisis escapes beyond } \\
\text { boundaries of } \\
\text { organization }\end{array}$ & $\begin{array}{l}\text { Damage to those } \\
\text { beyond organizational } \\
\text { boundaries is slight }\end{array}$ & $\begin{array}{l}\text { Major impact is confined } \\
\text { within organization }\end{array}$ \\
Business \\
Resumption
\end{tabular}




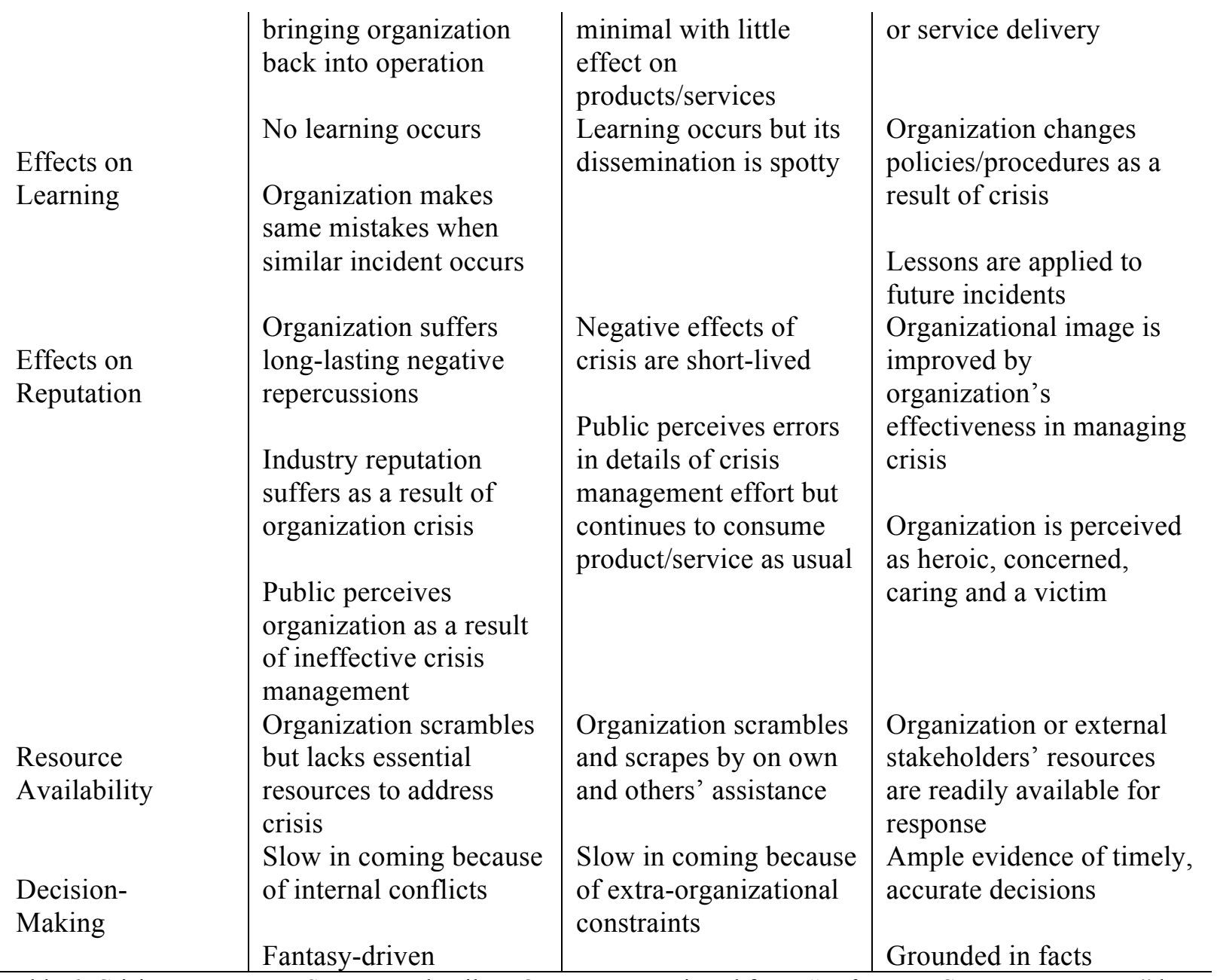

Table 6. Crisis Management Success and Failure Outcomes. Retrieved from "Reframing Crisis Management" by C.M Pearson \& J.A. Clair, 1998, Academy of Management Review, 23(1), p. 13. Copyright 2008 by Arjen Boin.

Image repair is closely linked to brand equity and reputation, which is how a brand is viewed by others and measured against its competitors. Brand equity and reputation can be measured differently according to many studies; however this research paper will take a similar stance to Aaker's measure of "Brand Equity Ten," (1996) which are ten measures of brand equity grouped in five categories, and are set to track and evaluate brand equity. Some of these measures will be used for the analysis of the case evaluated; as such there will be further discussion in the methodology section. 


\section{Strengths and weaknesses of studies / gaps in research}

Ulmer, Sellnow \& Seeger (2013) discuss the misconceptions associated with crises, stating that many times, organizations fail to see the opportunities in crises, as there is tendency to view crises from the perspective of threat. Although this is not a weakness in the literature, it is a weakness examined in the practice of crisis communication management. This research paper also takes this perspective and strives to close the gap between finding opportunities in crisis communications through the use of social media channels. There is not enough research testing crisis communication best practices against recent crisis cases. Therefore the remainder of this research will aim to provide social media strategies based on current theory and social media analytics, and in doing so will contribute to close the gap in literature. It is important to note that following this research, there is still much work left to transpose on evaluating and reiterating best practices in social media for crisis communication cases. 


\section{METHODOLOGY}

\section{Research Questions}

R1 - How can Unmetric analysis be deployed by managers to improve crisis management efforts?

R2 - How did social media on Twitter contribute to Chipotle's successful handling of the crisis?

\section{Twitter}

The research examines Chipotle's activity on social media, namely its Twitter account (@ChipotleTweets),with an end-goal of determining some best practices in crisis communication strategies through social media channels. Chipotle has a public Application Program Interface (API) which means that information from Twitter can easily be retrieved in the past. Twitter has been chosen as the platform allows for more conversation among users as well as between user and brand. It is important to mention that the company's corporate website, although very detailed, does not consist of a social media platform as it does not foster interaction among users, nor does it require the creation of a user account.

\section{Theoretical Frameworks}

In order to gain a better understanding this case, it will be examined through the lens of Coombs' Situational Crisis Communication Theory (SCCT), a framework which helps organizations protect their reputations following a crisis. The first step is to determine the crisis cluster type and, second, the crisis strategy (refer to Tables 2 and 3 in the literature review section). The cluster types are accidental, preventable, and intentional. The crisis strategies listed by Coombs are the following: denying, diminishing, rebuilding, and bolstering. Coombs' model has been selected to identify the type of crisis and strategies used as the model suggests that crisis response strategies should be used according to the crisis responsibility (what level of 
responsibility stakeholders attribute to the organization). By evaluating the appropriateness of crisis strategies used, we can then determine if the crisis outcome is successful or has failed.

\section{Unmetric}

Data from Twitter will be gathered from Chipotle's Twitter account (@ChitpotleTweets) through Unmetric, an online analytics tool which provides account metrics such as follower count, engagement scores, post frequency, common hashtags, and replies. In particular, its measure of engagement score differentiates the platform from other data analytics services. Engagement scores measure audience responses to the company's proactive tweets and activity on Twitter - these responses are measured by weighing audience interactions on brand content (such as "likes", comments, shares, replies, and retweets) based on their importance. This total is divided by the number of brand fans and followers who actively receive and view this content (Audience Reception Rate). The formula has been created based on Unmetric's research - the company recognizes that engagement scores cannot simply be measured by number of likes, comments, shares, or re-tweets. Rather, evidence from a study at Stanford (Bernstein et al., 2013) shows that the audience reached by a user post varies as a function of the number of friends the user already has. In other words, if a Chipotle follower also follows 10,000 other users, the chance of the user seeing Chipotle's post is lower than a user who follows 100 accounts. Moreover, in a different study, a team who analyzed large datasets of tweets built a retweet model, suggesting that if a user has a large following, it is more likely that a tweet will be retweeted (Suh, Hong, Pirolli \& Chi, 2010). That said, in the Unmetric engagement formula, shares and re-tweets are weighed higher than favourites and likes as they amplify audience reach of a tweet (Unmetric, 2016). The engagement score doesn't penalize brands with many followers, states Unmetric. 


\section{Twitter Engagement Score Formula \\ (\# Favourited Tweets + \# Replies + \# Tweets) 10000}

Audience Reception Rate

Another measure used through Unmetric is tweet counts. Unmetric gathered tweets from all users directed at Chipotle, and all tweets posted from Chipotle (either as a proactive tweet, or a response to another tweet) - based on this, a keyword search (e.g. "E. coli") was done to count the number of times it had appeared in the database of tweets.

Understanding various types of tweets may also help determine what audiences prefer, and in which context. The tweets may be "mentions" - which refers to mentioning another Twitter user in the tweet; they may be proactive, which is a tweet written by the user not responding to another tweet; they may contain a link to another source, such as a video, news clip, or image; they can be a reply to another users' tweet; or a "re-tweet," which is essentially taking a tweet and re-posting it on one's own Twitter page.

Unmetric allows for the comparison of brands in similar sectors and provides easy-toread results in both excel and Power Point formats. Unmetric also offers a free trial for new users. In this case, metrics will be compared from three periods: pre-crisis from March 1, 2015, to July 31, 2015; during crisis from October 1, 2015, to March 1, 2016; and post-crisis, from April 1, 2016, to July 9, 2016.

\section{Brand Equity}

After Twitter data has been gathered, there will be an overview of the company's sales figures before, during, and after the crisis, using elements from Aaker's model of "Brand Equity Ten" (1996), which lists ten measures that define brand equity. The elements used from Aaker's concept for the purpose of this research are the following: price premium, which is an important 
defining element of brand loyalty as it represents what a customer would pay for the brand in comparison to competitors. The second element is perceived quality - that is, compared to other brands, does Chipotle have high quality food? Is the quality consistent? The third and last element evaluated is market share, which refers to the performance of a brand based on sales or market share. In addition to this, we will look at Chipotle's overall point of difference (POD) with regards to its product and consumer base, as this certainly may be a factor in the social media strategy and type of content shared online.

\section{Crisis Outcome Measure}

Finally, we will determine if the crisis was successfully managed first based on the crisis outcome measure, based on Pearson \& Clair's model which outlines examples of failure, success and middle-ground crisis management outcomes (Table 6). This model has been used as it is first suggested model for a success and failure weighing psychological, socio-political, and technological elements (Pearson \& Clair, 1998). The authors outline seven crisis concerns, all of which play a role in determining a crisis outcome measure. First is signal detection, which refers to how well and early the organization detects the crisis and responds to it. Second is incident containment, that is how well the organization can contain the crisis - or does it cause damage to stakeholders? Third is business resumption, which refers to the operation of areas of the organization which are most affected by the crisis. Fourth is effect on learning, which refers to the organization applying changes to company policies and procedures as a result of the crisis. Fifth is effect on reputation, defined by the time of reputation damage (long lasting versus short lasting), and if the industry as a whole is affected by the crisis. Sixth is resources availability that is how ready the organization is to manage a crisis. Finally, the last crisis concern is 
decision-making, which is how quickly the organization makes decisions with regards to crisis management strategies.

It is important to note that Pearson \& Clair's outcome measures are determined based on research of online content, news sources such as $\mathrm{CNN}, \mathrm{CBC}$, Bloomberg News, and Fortune Magazine, and company sales figures. In order to determine the appropriate crisis outcome (success, middle, failure), a numeric value is attributed to each crisis concern, each of which are weighted equally ( 1 point for each crisis concern). The final outcome is determined by calculating the total from each category (failure, midground and success), where the highest number in each category would represent the outcome. The following discussion section will address the variables listed, answer the three research questions, and finally propose recommendations for future crisis case managers. 


\section{FINDINGS \& DISCUSSION}

\section{Crisis \& Strategies}

The following analysis determines the type of crisis "cluster" and strategies used based on Coombs' SCCT theory. In this situation, the Chipotle case could be viewed as accidental, where the incident is unintentional - or preventable, where there are strong attributions of crisis responsibility and the organization is at fault. It could very well be accidental, as the source of E. coli was not identified nor was it traced to Chipotle activity by the FDA and CDC, which means the company may not have had control over the outbreaks, and is not legally at fault for poor food preparation, sourcing, or transportation. Some may perceive the crisis to be preventable, meaning the company was fully responsible for preventing any disease outbreaks. In this case, due to the severity and length of the crisis (3 to 4 months), we take the stance of preventable. Although the source of E. coli was not found, it does not mean that Chipotle was not at fault. Furthermore, Chipotle has been a leader in offering fresh fast food in the United States, which means consumers' expectations are high on the company to deliver fresh services and products. Not being able to meet these expectations puts the company in a more vulnerable situation.

The strategies used to address the crisis on social media based on Coomb's theory of SCCT fall under both primary and secondary categories. As stated previously, as response strategies become more accommodative and show more concern for victims, the involved stakeholders perceive the organization as taking greater responsibility for the crisis. The primary crisis strategies used are (1) excuse - meaning the company minimized organizational responsibility by not addressing the issue on social media when it should have (i.e. after the first few incidents in October). As discussed in the literature review, it is important for crisis managers to address issues in a timely manner in order to gain the public's trust, and ensure that 
the organization's best image is represented (Sellnow, Ulmer, Seeger, 2007; Coombs, 2007).

Secondly, Chipotle used apology - the organization eventually took full responsibility for the issue by closing down up to 43 stores in the United States and announced it on both traditional and social media. However, it took four months for CEO Steve Ells to formally apologize during the company-wide meeting, which was tweeted live: "Deeply sorry that some people became ill after eating Chipotle. Committed to make sure it won't happen again. \#ChipotleAllTeam”. Although the apology was given, it did not come directly from the CEO on Twitter. It is a best practice that organizations that are perceived at fault address the issue and provide an authentic apology early on (Coombs, 2007). The company also offered free burritos intermittently (at some locations), which was part of the compensation strategy. It did not, however, compensate those who were directly affected by E. coli.

The secondary crisis strategies used was ingratiation, where crisis managers praise stakeholders or will remind them of good works done by the company. Chipotle reminded consumers about its mission, "Food with Integrity" which is all about simple, fresh food without artificial flavors or fillers, just raw ingredients sourced from farms rather than factories (Chipotle, 2016). The company also reminded its customers of the good work done by the organization, especially during the company-wide meeting on February 8. Chipotle's Twitter feed also reinforced the positivity and points of brand differentiation throughout the crisis, differentiating itself from fast-food chains, as seen in Figure 1 below:

\section{Figure 1}

\section{Chipotle Brand Tweets (During Crisis - Period 1 October 2015 to 1 March 2016)}

\begin{tabular}{lll}
\hline Proactive Tweet & Tweet URL & Created at \\
\hline $\begin{array}{l}\text { Unnecessary ingredients are creepy: } \\
\text { http://t.co/LGIr3LEwmu \#Boorito }\end{array}$ & http://www.twitter.com/ChipotleTweets/status & $2015-10-05$ \\
https:/t.co/VVlFzI55oX & $/ 651056344330403840$ & $11: 28$ \\
\hline
\end{tabular}


Scarier than ghosts ghouls or goblins. See how creepy typical fast food can be: http://t.co/LGIr3LEwmu \#Boorito http://www.twitter.com/ChipotleTweets/status $2015-10-05$ http://t.co/ujoW20KbLA $/ 651109651090509824$

Typical fast food has creepy

additives like Polysorbate 80.

Sounds like an evil robot?\#Boorito

is 10 days away:

http://www.twitter.com/ChipotleTweets/status

$2015-10-21$

https://t.co/1HmW7QxwEh

$/ 656907808697393152$

$15: 00$

Ghosts don't need cowboy hats.

Food doesn't need additives. Score a http://www.twitter.com/ChipotleTweets/status

\$3 Boorito on Halloween.

$/ 658388816126939140$

$2015-10-25$

$17: 05$

Typical fast food has creepy additives like Natamycin. Ew Natamyburrito. \#Boorito is 3 days away: https://t.co/1HmW7QfVfH http://www.twitter.com/ChipotleTweets/status $2015-10-28$ /659535156944859137 21:00

Figure 1. Chipotle Brand Tweets illustrates its differentiation to fast-food restaurants (during crisis period examined). Figure created from Tweets obtained on Chipotle's Twitter feed from October 1, 2015 to March 1, 2016. https://twitter.com/ChipotleTweets Copyright 2016 by Chipotle Mexican Grill.

To conclude, it has been determined that Chipotle's crisis was preventable, and based on information gathered, the strategies used were excuse, apology, and ingratiation. Whether or not these strategies were effective in managing this crisis will be determined following Twitter analysis and sales figures, where a measure of outcome success measures will be performed.

\section{Unmetric Data}

The following information has been gathered from social media analytics tool Unmetric. As seen in Table 7, three data-sets for three separate periods (pre-crisis, during, and post-crisis) were observed. It is important to note the third period (post-crisis) is shorter in length due to the recent timeframe of the case and this research. 
Table 7

Unmetric data analytics for three periods examined

\begin{tabular}{|c|c|c|c|}
\hline Variables & $\begin{array}{l}\text { March } 1 / 15 \text { to } \\
\text { July 31/15 }\end{array}$ & $\begin{array}{l}\text { October 1/15 to March } \\
\text { 1/16 }\end{array}$ & $\begin{array}{l}\text { April 1/16 to } \\
\text { July 9/16 }\end{array}$ \\
\hline $\begin{array}{l}\text { Day count in period } \\
\text { evaluated }\end{array}$ & 153 & 153 & 100 \\
\hline Follower Growth & $6.5 \%$ & $6 \%$ & $4.8 \%$ \\
\hline Engagement Score* & 383 & 566 & 863 \\
\hline Number of Tweets & 42,000 & 44,000 & 36,000 \\
\hline $\begin{array}{l}\text { Average Response } \\
\text { Time (ART) }\end{array}$ & 43 minutes & 33 minutes & 51 minutes \\
\hline Common Hashtags & \#chipotle & \#boorito & \#chipotle101 \\
\hline Used & $\begin{array}{l}\text { \#lovewins } \\
\text { \#chipotlecultivate } \\
\text { \#cultivatingthought }\end{array}$ & $\begin{array}{l}\text { \#e.coli } \\
\text { \#chipotleallteam } \\
\text { \#raincheck }\end{array}$ & $\begin{array}{l}\text { \#waitinginlinethoughts } \\
\text { \#mplusplaces }\end{array}$ \\
\hline Influencers & $\begin{array}{l}\text { Vogue } \\
\text { Paul Coelho } \\
\text { People Magazine }\end{array}$ & $\begin{array}{l}\text { Kevin Hart } \\
\text { CNN } \\
\text { Today Show }\end{array}$ & $\mathrm{N} / \mathrm{A}$ \\
\hline
\end{tabular}

Table 7. Unmetric data analytics during three periods examined. Figure created from Unmetric data (see Tables and Figures 1-3).

The engagement score during the crisis is higher than pre-crisis, but lower than post-crisis - this could be attributed to a higher volume of tweets by Chipotle (an average of 290 tweets per day, higher than other periods examined). Interestingly, the average response time was much quicker during the crisis period (33 minutes) as users had more food-safety questions and comments during that time.

Interestingly, it took Chipotle quite a few days before announcing the E. coli outbreak on Twitter - although it was reported in the news (CNN, etc.) as early as October 2015, the company did not voluntarily address the issue on Twitter November 9, 2015, and even, then did not tweet many times about the outbreaks (Unmetric, 2016). 
The food safety trend is even noticeable as one of the common used hashtags was "\#ecoli". As for popularity of hashtags, one of the engagement scores was highest for \#chipotleallteam, which was a keyword used to explain meeting agenda items during the company-wide meeting on February 8 (see Figure 2). The influencers refer to other popular accounts on Twitter (also with a large following) who have mentioned Chipotle in a tweet. During the crisis, both CNN and the Today Show tweeted about Chipotle regarding the E. coli outbreaks, whereas before and after the crisis, influencers were not significant enough.

\section{Figure 2}

\section{Engagement score by Hashtag (@ChipotleTweets)}

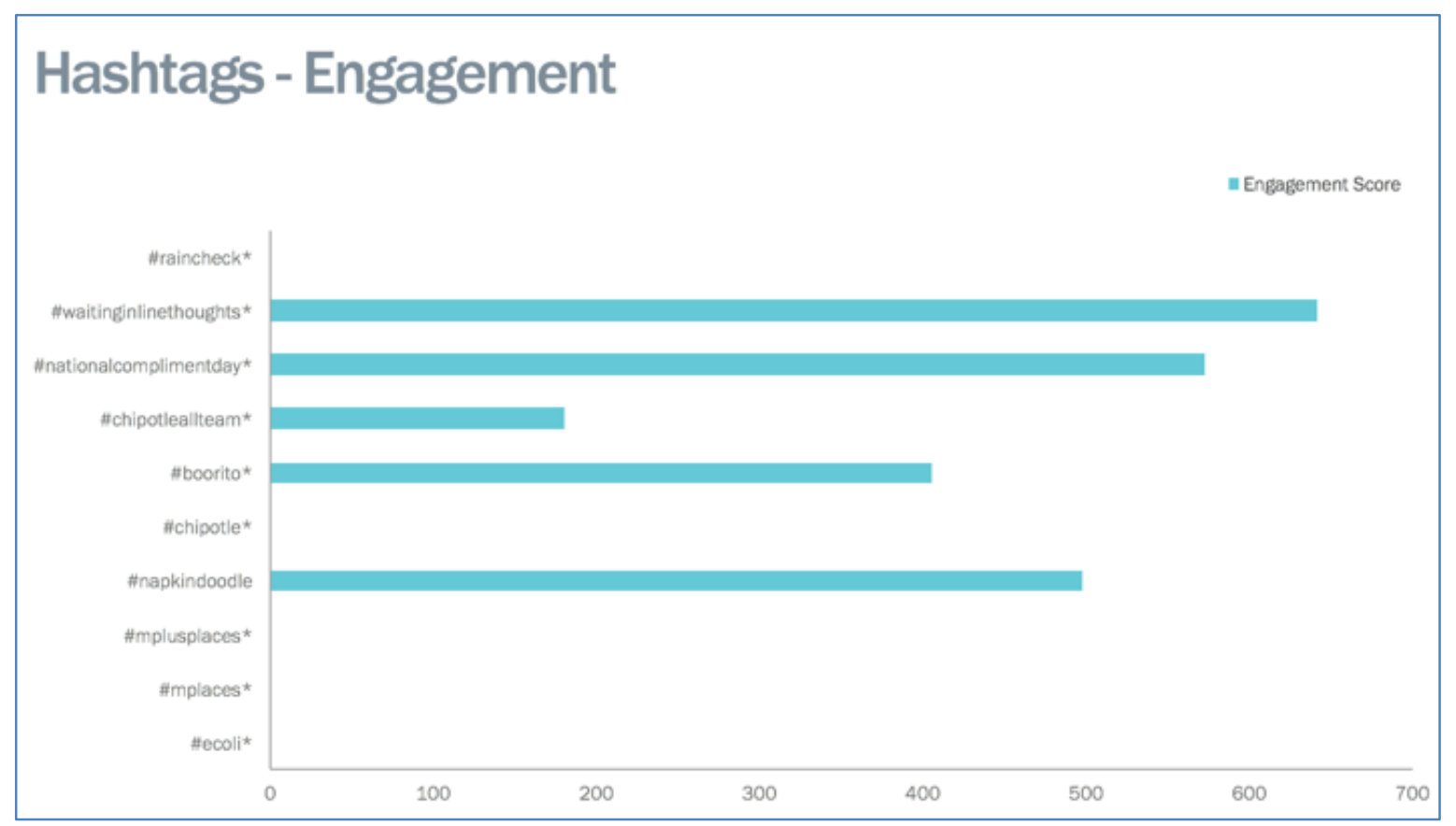

Figure 2. Engagement scores by hashtags. Obtained from Unmetric Data for crisis period observed (1 October 2015, to 1 March 2016).

Based on this information, it is evident that Chipotle acknowledged the E. coli crisis case on Twitter, but mostly used the platform to respond to users' concerns and questions ( $98 \%$ of tweets were replies to users - see Appendix C for examples). Interestingly, Chipotle did not mention the E. coli case (not even use of the word - as seen in Figure 2 above) before the 
company decided to close its stores nation-wide, where it provided live-tweets during the entire meeting. February 8th represents the day with highest amount of tweets related to its food-safety issues, understandably as stores were closed for consumers.

\section{Brand Equity}

As stated previously, elements from Aaker's "Brand Equity Ten” (1996) are used to evaluate the brand reputation throughout the case. The first element is price premium - in this case, Chipotle's menu is significantly more expensive than its competition (an average of $\$ 8.00$ per meal item), as they sell naturally-raised meat, organic produce and dairy without added hormones (Chipotle Investor Relations, 2016). Even so, there are many consumers who prefer Chipotle than other fast-food chains, which illustrate a strong brand loyalty.

The second element is perceived quality. Based on Chipotle's Food with Integrity Campaign and efforts to market, promote, and sell organic produce, many would attribute a high quality to the company's products. Chipotle has been known to offer fresh and healthy meals, quickly and at an affordable price - although usually pricier than the typical fast-food chains (such as Taco Bell or McDonald's), customers are guaranteed fresh meals which are prepared on the spot. However, due to changes in food health and safety measures, many would see this as an inconsistent measure. Therefore, the perceived quality measure is viewed as neutral.

Finally, market share illustrates the brand performance based on sales and market share. Chipotle's primary competitors are (1) fast food chain Qdoba, a Mexican-style fast-food eatery; (2) Mswg, who operates more than 400 Moe's Southwest Grill eateries in the United States; (3) Fresh Enterprises, which owns Baja Fresh, a Tex-Mex restaurant style; (4) Rubio's Coastal Grill, a fast-food restaurant chain specializing in Mexican food, and finally to a certain extent; (4) Taco Bell - the market leader the Mexican-style fast food restaurants (Investopedia, 2015). Owned by 
Yum Brands (who also owns Pizza Hut and KFC), Taco Bell operates over 6,000 stores in the United States. Although Chipotle does not compete directly with Taco Bell due to its size and brand reputation, it is interesting to observe differences between both companies.

Chipotle is a publicly-traded company (CMG), which really expanded after McDonald's invested in the company in 1998. Chipotle's initial public offering in 2006 was one of the most successful restaurant launches in U.S. history, as the stock doubled on its first day of trading (Investopedia, 2015). According to Chipotle's sales figures, it has increased in restaurant sales by 5.6\% in 2013 and 16.8\% in 2014 (Chipotle Investor Relations, 2014). In 2015, revenues continued to rise in the first three quarters but the company reached a low in its 2015 fourth quarter, during the time of crisis - as profits sunk $44 \%$ (as opposed to the previous year) and in February 2016, stock was down 40\% (Investopedia, 2016). In the first quarter of 2016, sales (compared to 2015) were down 29.7\%, which could be attributed to the crisis case, as fewer customers frequented stores. Furthermore, Chipotle had a net loss of \$26.4 million in Q1, as opposed to a net income of \$122.6 million in Q1 of 2015 (Chipotle Investor Relations, 2016). In comparison to last years' Q2, Chipotle's revenue decreased by almost $17 \%$ and net income was \$25.6 million, a decrease from \$140.2 million last year (Chipotle Investor Relations, 2016). Interestingly, when Chipotle decided to close its doors on February 8, 2016 for a company-wide meeting, other fast-food chains took the opportunity to ridicule the company. Moe's Southwest Grill posted an ad on USA Today, stating "We're open, especially on February 8th." (Time Magazine, 2016). Dos Toros also did something similar by tweeting 'Breaking News: we're open for lunch, as usual” (Time Magazine, 2016). Finally, Qdoba, one of Chipotle's largest competitors, also tweeted on February 8 “Hunger doesn't accept rain checks" (see Appendix A). 
In closing, although not part of Aaker's “Brand Equity Ten” (1996) list, it is important to examine Chipotle's customer base. According to the PEW Research Centre's findings on Social Media demographics, Twitter is more popular among younger adults $-30 \%$ of online adults under 50 use Twitter, compared to $11 \%$ of online adults ages 50 and older. During a statement of Chipotle's 2013 third quarter results, CEO Steve Ells stated that its customers were Millennials who didn't mind skipping fast food in favour of restaurants like Chipotle (Jones in Market Realist, 2014). That said, Chipotle's main consumer base is among the Millennial generation (born between 1980 to year 2000), which relates to the company's fresh produce appeal and marketing strategy and higher priced items. This will be further discussed in the next paragraphs.

\section{Point of Difference}

There are a few elements or "points of differentiation" (POD) that separate Chipotle from its competitors. First and foremost is Chipotle's "Food with Integrity Campaign", which strongly appeals to Millennials (those born between years 1980-2000). Chipotle is "all about simple, fresh food without artificial flavors or fillers. Just genuine raw ingredients and their individual, delectable flavors. [They] source from farms rather than factories, and spend a lot more on ingredients than many other restaurants" (Chipotle Food with Integrity, par. 6). According to a report done by Jeffries, an investment and research firm, Millennials certainly enjoy convenient and fast food, but they are also more willing to pay for fresh and healthy food (Hoffman in Forbes, 2012). This is especially true in Chipotle's case, as the price of meals is quite higher compared to its competitors. For example, the price of a burrito is just over $\$ 8.00$ (USD) whereas Taco Bell sells them for just over \$2.00 USD. Although organic food seems to be a growing trend, experts have weighed on the difficulties of carrying organic products: "as it turns out, when [a] business model is built on the premise of serving fresh food [...] your supply chain 
becomes much more complex. And complexity means more risk" (Alba in Wired Magazine, 2016) - an interesting point for Chipotle to consider.

In addition to marketing its fresh food advantage, Chipotle has been transparent about the presence of genetically modified organisms (GMOs) in its food. In 2013, it disclosed that some of its products had GMOs, and in 2015 made the switch to offer food made only with non-GMO ingredients (Chipotle Food with Integrity, 2016). This type of transparency demonstrates the overall brand position and understanding of today's consumer; which is that Millennials are quite skeptical, and question the authenticity and transparency of content on a regular basis (Friedman in Forbes, 2016).

Not only are Chipotle's meals made with “fresher" foods than typical fast-food chains, but customers are able to customize their meals. Chipotle offers a wide variety of vegetables, beans, cheeses, salsas, and sauces which can be used in combination with different meats and breads to create custom meals. Customization is another element which strongly appeals to Millennials. According to a research conducted by Accenture on shopping behaviours of consumers across 8 countries, results show that retailers must offer customizable products and services to remain relevant for Millennials (Outlook by Accenture, 2013). All in all, a combination of fresh products that can be easily customizable is a true recipe for success with the Millennial generation.

\section{Crisis Outcome Measure}

Now that data has been gathered, Pearson \& Clair's success measures will serve to rate the success of Chipotle's crisis. The table below illustrates the outcome measure table along with the score for each outcome variable. 
As for signal detection, the outcome selected was midground - which means signals of crisis sent the organization into a state of alertness. Although Chipotle was relatively quick at closing its stores, the company CEO did not formally apologize on a large scale. Furthermore, based on social media activity, the company did not Tweet many alerts until it was forced to close 43 stores in November. Chipotle did demonstrate an awareness of the crisis by responding to users' tweets on Twitter, and finally, it reinforced its mandate of providing fresh food through its Twitter feed. The signal detection can therefore fall within the midground outcome.

Second, for incident containment, the crisis certainly escaped beyond the boundaries of the organization - not only did sales and investor stock plummet, but individuals became sick (some announcing it on social media) thus amplifying the issue, other "influencers" tweeted about the issue online, and finally, one of their executives was caught in a drug scandal in the midst of the crisis. This can be attributed to a failure outcome as the incident seeped out of the company's control. It is important to note that Chipotle took strategic and important measures to address the crisis; however this crisis concern examines the containment portion.

As for business resumption, in this case 43 stores with identified cases of E. coli were closed temporarily for investigations. Although those stores only represented about $2 \%$ of company revenues (Bloomberg, 2015), it was important for Chipotle to demonstrate the issue was considered seriously. Furthermore, the nationwide store closure on February 8, 2016 also demonstrates the company's commitment to re-stating a new food and health safety policy, even if it means losing profit during an economically unstable time. As stated previously, sales and stock certainly decreased in Q4 of 2015, which illustrates the impact of this case on company revenues. Based on these factors, the midground outcome has been selected as the most appropriate outcome. 
As for effects on learning, this certainly occurred following the case as the company introduced a new food safety policy in December 2015, and held a company-wide meeting to discuss new safety measures with all of its employees in February 2016. Moreover, the company announced that it would not give out executive bonuses at the end of 2015 due to a significant decrease in revenues. Finally, Chipotle decided to halt the opening of new stores it had planned on opening in 2016, as it was not financially feasible. These elements show the company's commitment in changing its safety measures and its understanding that it must regain trust of customers prior to engaging in business development activity. This outcome can be rated as a success measure.

The fifth crisis measure relates to the effect on the company's reputation. We have discussed elements of the brand equity in a previous section; however this model seeks to look at the crisis' lasting effects on the company. In comparison to last years' Q2, Chipotle's revenue decreased by almost $17 \%$ and net income was $\$ 25.6$ million, a decrease from $\$ 140.2$ million last year (Chipotle Investor Relations, 2016). During Q2, Chipotle engaged in a new marketing campaign called Chiptopia - a summer rewards program created to reward loyal customers. It also opened 58 new restaurants during this time, a factor that may have certainly halted revenues. Furthermore, Chipotle has lost its seat as the most popular Mexican restaurant chain after being first for the past three years. Moe's Southwest Grill, who operates fewer stores than Chipotle, has unseated the company to take on the title of most popular Mexican restaurant. Not only has the company lost its title, but it has fallen behind Taco Bell, Qdoba, and Baja Fresh, according to a 2016 survey by Harris Interactive who measured how consumers feel about restaurant chains. Based on this, the company is evidently making efforts to regain its position in the market as the crisis has affected their sales post-crisis. This would be a midground crisis outcome. Should the 
company continue to suffer financially in the next year or two, the success measure could be considered as a failure.

As for resources availability, Chipotle was fairly quick at making important decisions such as its store closures - it was prepared to take a financial hit during this time. The company also offered burritos as compensation in other stores. Although this strategy may not have been the most effective, the company acted quickly - this is an indication of substantial resources at hand. Interestingly, social media content did not mirror this activity as the company barely tweeted about the case. On the other hand, Chipotle was quick at responding to users' concerns (ART of 33 minutes) and launched marketing campaigns in order to maintain their brand image. This concern would be measured as a success. It is important to remember that resource availability is highly related to an organization's financials and revenues. With more capital to work with, a company may be able to make riskier decisions.

The seventh and last crisis concern is decision-making. When looking at decisions made, it is important to observe those that affect consumers directly. Chipotle did choose to close many of its stores rather quickly, which was important to demonstrate it was taking the issue seriously. We would consider this to be a successful concern. 


\section{Table 8}

\section{Outcome Measure Table \& Results}

\begin{tabular}{llll}
\hline Crisis Concern & $\begin{array}{l}\text { Failure } \\
\text { Outcomes }\end{array}$ & $\begin{array}{l}\text { Midground } \\
\text { Outcomes }\end{array}$ & Success \\
\hline 1. Signal Detection & & 1 point & \\
\hline 2. Incident Containment & 1 point & & \\
\hline 3. Business Resumption & & 1 point & \\
\hline 4. Effects on Learning & & 1 point \\
\hline 5. Effects on Reputation & & 1point & \\
\hline 6. Resource Availability & & & 1 point \\
\hline 7. Decision-Making & & & 1 point \\
\hline TOTAL & $\mathbf{1}$ & $\mathbf{3}$ & $\mathbf{3}$ \\
\hline
\end{tabular}

Table 8. Outcome Measure Table with points attributed for each crisis concern. Adapted from "Reframing Crisis Management" by C.M Pearson \& J.A. Clair, 1998, Academy of Management Review, 23(1), p. 13. Copyright 2008 by Arjen Boin.

Based on the results from Table 8, it is evident that Chipotle had some success with selected variables in its crisis management. However it did not succeed at containing the incident very well, as many stakeholders were severely affected. Overall, Chipotle would fall in the midlower crisis outcome. To conclude, although Chipotle had successes in its crisis management strategy, there are definitely opportunities for improvement in the future. The following section will address some of these opportunities, and how a company like Chipotle can best use social media to manage some of the variables discussed above.

\section{Research Questions}

Now that findings related to data, brand equity, and crisis type have been discussed, the following research questions may be answered.

R1 - How can Unmetric analysis be deployed by managers to improve crisis management efforts?

The use of data analytics tool Unmetric has proven to be effective in the evaluation of social media platforms during the Chipotle E. coli case. While it cannot be determined whether 
or not Chipotle gathered social media analytics during the time of crisis, it is evident that analytics would certainly help crisis managers devise appropriate strategies to overcome or reduce the impact the case. Although Unmetric is one of many online analytics tools and was used during a short period of time, it has provided valuable information. Based on the data gathered, listed below are some of the recommended variables to examine during a crisis case.

\section{Engagement Scores}

As mentioned previously, Unmetric calculates engagement scores, which measures the audience responses to the company's proactive tweets (i.e. tweets that stem from the account holder, not a response to another tweet) and activity on Twitter - these responses are measured by weighing audience interactions on brand content (such as "likes", comments, shares, replies, and retweets) based on their importance (Unmetric, 2016). Understanding engagement scores in relation to specific tweets, for example a tweet announcing store closures, may identify the impact of the crisis on users. Engagement scores may also be analyzed in comparison to the time of a tweet - if an organization notices a trend of higher engagement scores in the evenings, it may consider posting content in the evenings to reach a larger amount of users. A high engagement score is desired, as is means that users are commenting, sharing, and liking the content posted. Unmetric's engagement score can be modified based on the business goals.

\section{Keywords \& Hashtags Used}

In this case, E. coli had been mentioned over 900 times during the period examined. In addition to this, it is possible to identify the user, date of post, and whether other users have retweeted the same tweet. This information would be essential for a company facing a similar type of crisis, as they are able to reach out to each individual affected, and monitor any viral trends by counting keyword frequencies and at which times they appear. Chipotle responded to many of its 
customers' health and food safety-related questions and concerns with an average response time of 33 minutes, which is important to maintain a relationship with consumers. Knowing this information would also allow the company to understand when their users are tweeting most, and in turn could post a proactive tweet in anticipation for this. Furthermore, understanding key words helps monitor the type of conversations or trends occurring around the company. For example, among many other words, "health" was a used keyword during the crisis period, which illustrates types of conversations had regarding the company. The Figure 3 below illustrates the top hashtags used in the crisis case context.

\section{Figure 3}

Volume of Tweets with Hashtags

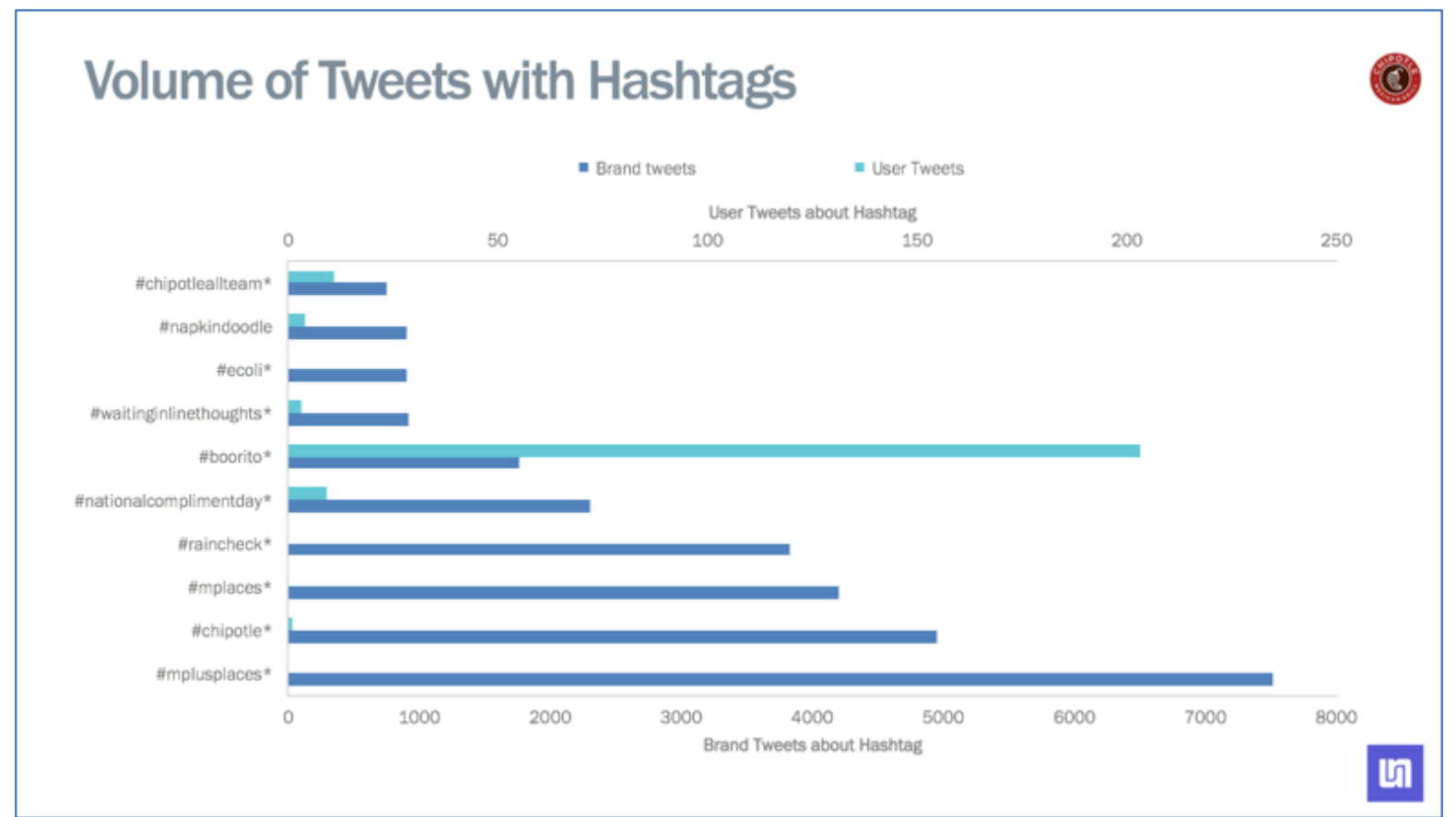

Figure 3. Volume of Tweets with Hashtags. Obtained from Unmetric Data for crisis period observed (1 October 2015, to 1 March 2016).

\section{Types of tweets}

In this case, Chipotle used a combination of simple proactive tweets, with some links to external sources. By taking it a step further, it would be recommended to evaluate the 
engagement of different types of tweets to determine if the audience prefers one type over another. The Figure 4 below illustrates Chipotle's tweet types over the crisis period examined. We can see that that tweet types with highest engagement were plain text, which refers to simple messages, with no links, mentions, or hashtags used.

\section{Figure 4}

\section{Brand Tweet Types}

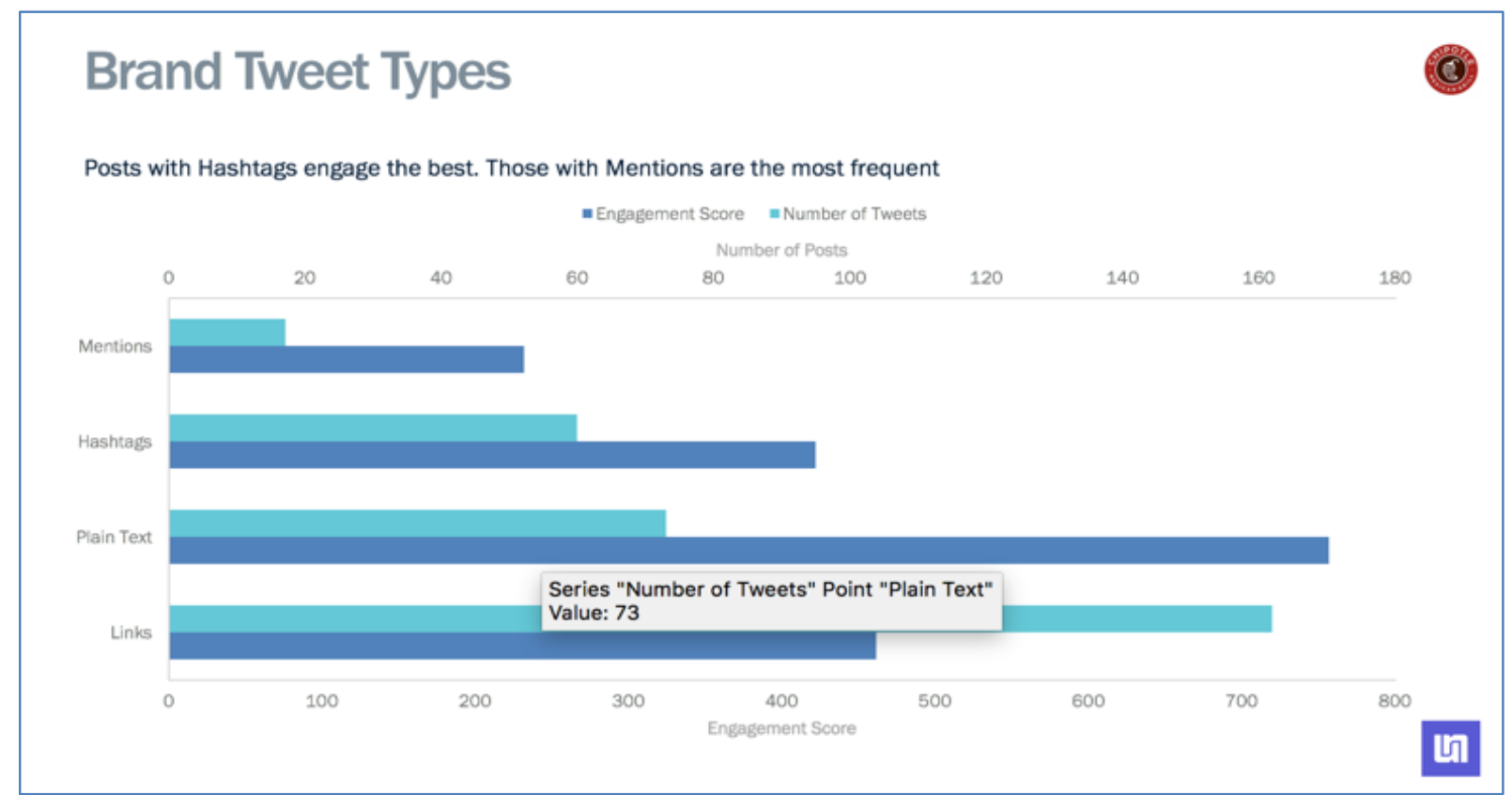

Figure 3. Chipotle's Tweet Types. Obtained from Unmetric Data for crisis period observed (1 October 2015 , to 1 March 2016).

\section{Follower Profile}

Although Unmetric did not provide a follower profile, understanding social media followers may certainly help in tailoring content, message intent, and frequency of posts on Twitter. Twitter Analytics' dashboard function allows account holders to monitor interests and demographic of its followers. This information was not obtained as the main account holder can only access this information. However, based on the prominence in younger users on Twitter (i.e. 
18-29) (Pew Research Centre, 2015) and Chipotle's young consumer base (Millennials; 19802000 and some Generation Z; 1960-1980), an appropriate strategy can be devised.

\section{R2 - How did Twitter contribute to Chipotle's handling of the crisis?}

Based on data gathered, Twitter certainly was used to communicate elements of the crisis case (e.g. store closures, company-wide meeting), but was not used as a means to inform users about news content, such as formal investigations. It is important to remind that Chipotle's target consumer base is teenagers, who also form a large part of their Twitter following. Chipotle may not have proactively addressed the crisis on Twitter for fear of starting viral "Twitter Wars" between users and other brands - a trend that had started earlier as described in the previous section. Or perhaps the strategy was to shelter the target consumer base in order to avoid plummeting sales and damage to brand reputation, which had already started to fall. Regardless, in any crisis that involves risk and potential safety concerns, it is imperative that organizations address the issue right away. The reality of today's digital economy is that information must be posted where users are - in this case, the majority of Chipotle's consumers are technology users, as such it is recommended that information should be made available to them through social platforms.

Twitter was used to communicate very generally, infrequently, high-level, information that would be essential for consumer safety, and information that would help mitigate reputational damages to the brand. For example, Chipotle did not proactively tweet many times about the crisis over the period examined; however it definitely responded to many users' concerns and questions about food safety measures in its stores. 


\section{CONCLUSION}

Based on the crisis outcome measures, the following strategies are recommended for Twitter:

Measure, measure, measure: it is important for all organizations to understand their digital following, online trends, and how to best create a sense of community between the brand and consumer. A few elements of measure have been discussed in previous pages - these are essential to know before a crisis occurs, as the organization can appropriately devise strategies based on the audience profile.

Using hashtags is important to generate trends and interest from users - for example, \#chipotleallteam was used as a positive hashtag and crisis strategy to illustrate the work done by company to address and rectify the issue). It also creates a sense of community between consumer and brand, as both parties can use the hashtag.

Understanding the user base - Millennials, which represent Chipotle's largest consumer base, as well as Twitter's main user demographic, generally have more liberal views and like an open platform to express themselves during times of crisis (PEW Research Centre, 2010). The ability to directly reach out to Chipotle creates a healthy discussion and provides an open environment for consumers. For a different target audience such as baby boomers, the strategy would differ as the generation is not as comfortable with technology and less present on social media (PEW Research Centre, 2010).

Providing a timely response is important (Average Response Time) - companies are now competing for customers. Being able to provide timely responses is crucial to customer satisfaction, which in turn increases customer loyalty and trust. According to a 2013 study by Lithium Technologies (2013), a social customer experience platform, online users high 
expectations for quick responses. In fact, $53 \%$ of users who expect a brand to respond to their question or tweet expect that response come in less than an hour. If the tweet is a complaint, $72 \%$ of users will expect an answer. Furthermore, if the company does not meet these expectations, $38 \%$ feel more negative about the brand, and $60 \%$ will take negative action to express themselves. Chipotle was quick to provide responses (Average Response Time of 33 minutes during the crisis period), which demonstrates their understanding of this metric.

Having brand influencers: brand influencers are other companies or individuals that may tweet on behalf of the company, who also have a significant following. This can be a negative or positive aspect of crisis management. For example, brands with large followings tweeted about the Chipotle E. coli outbreak (e.g. CNN, The Today Show), which was not always done in a positive way. A strategy would be for companies to partner with other Twitter users in order to engage in positive conversations.

Providing personalized response provides a better connection between customer and brand. When Chipotle addressed its users' concerns on Twitter, many times it included a manager name to indicate there was real individual responding to the tweet. A study conducted by Twitter in 2015 surveyed over 14,000 users who follow or interacted with a company's customer service, and showed that in order to build relationships with customers, it is important to be personal - that is including both the brand's Twitter handle as well as the representative's user name in the response. In fact, $77 \%$ of consumers are likely to recommend a brand following a personalized customer service interaction.

To conclude, some of these strategies contributed to Chipotle's outcome; however these would require further testing in a similar environment and industry. As examined in Coombs' SCCT model, the use of crisis strategies depends on the type of crisis the organization is facing. 
To conclude, the following matrix has been created based on Coombs' model, using a combination of the author's crisis clusters and strategies in addition to social media strategies that have been determined based on the analysis of Chipotle's case. The social media strategies have been crafted in relation to the level of crisis responsibility attribution (i.e. how stakeholders view the organization in question).

Table 8

Matrix combining Coombs' \& Social Media Strategies

\begin{tabular}{|c|c|c|}
\hline Crisis Cluster & Crisis Strategy & Social Strategies \\
\hline Accidental $\rightarrow$ & $\begin{array}{l}\text { Diminish - convince stakeholders the } \\
\text { crisis is not as bad as people think }\end{array}$ & $\begin{array}{l}\text { Post often, post fast } \\
\text { Consistent message across platforms } \\
\text { and through time } \\
\text { Partner with positive brand influencers }\end{array}$ \\
\hline Victim $\rightarrow$ & $\begin{array}{l}\text { Deny- eliminates the link between } \\
\text { organization and crisis }\end{array}$ & $\begin{array}{l}\text { Use links referring to legitimate sources } \\
\text { Post facts } \\
\text { Safety first }\end{array}$ \\
\hline Preventable $\rightarrow$ & $\begin{array}{l}\text { Rebuild - suggests that organizations } \\
\text { should compensate affected } \\
\text { stakeholders for errors }\end{array}$ & $\begin{array}{l}\text { Marketing and promotional campaigns } \\
\text { (\#trends) } \\
\text { Social media apology } \\
\text { Personalized responses }\end{array}$ \\
\hline
\end{tabular}

Table 8. Matrix combining Coomb's crisis strategies and clusters and social media strategies based on research. Adapted from "Protecting Organization Reputations During a Crisis: The Development and Application of Situational Crisis Communication Theory”, by T. Coombs, 2007, Corporate Reputation Review, 10(3), p.168,170. Copyright 2007 by Palgrave Macmillan Ltd.

For accidental crises, not only is it important for organizations to keep the same messages across platforms in order to avoid rumors and to ensure the organization protects its image, but it is recommended to post often and quickly. It would also be beneficial to use brand influencers (users with a large following - a concept used by Unmetric), that would post consistent content on behalf of the brand or company. That way, the message would be reinforced and further accepted as it is coming from a popular or legitimate source. 
For victim crises, where the organization does not have control over the situation, it is recommended to post links to legitimate sources which would direct users to news sources or scientifically-proven facts that defend the organization. These types of crisis usually involve natural disasters or events that the company cannot control; therefore demonstrating an understanding and concern for customer safety is of utmost importance.

Finally, for the preventable crisis, the organization should first apologize across platforms (not just through traditional media) using the voice or name of a known figure with the company. In order to re-gain customer loyalty and demonstrate an understanding of customer frustrations, it would be encouraged to craft marketing strategies and social media trends online, which would help turn the brand image to a more positive one. Although these strategies are not fully tested and exhaustive, they provide a foundation for crisis managers to address potential crises in the digital age. This matrix may help crisis managers better respond to crisis situations on social media. We remind that in any crisis situation, it is important for decision-makers to understand the customer base and market positioning.

It is recommended for further research to test some variables, such as type of messages, use of hashtags, and influencers, to determine which element provides a higher success rate than others. It would also be interesting to develop a new crisis communication outcome measure, using elements that measure successful and failed social media variables. In this digital age, organizations must monitor all social media activity, not only during a crisis, but before and after as well. Monitoring activity on all social platforms allows the organization to better understand their users, monitor for potential issues to arise, and be prepared in the case of a minor or major crisis. By understanding their users, a company may better target their messages and posts, using a combination of strategies discussed in this research. Based on Chipotle's case, we have seen 
how crisis can heavily impact an organization. Going forward, all organizations can benefit from having social media strategies during a crisis situation - they will differ based on the industry, follower base, and type of crisis, but this is essential to organizational performance in the $21^{\text {st }}$ century. 


\section{APPENDICES}

Appendix A

Coombs' Situational Crisis Communication Theory Model (1995)

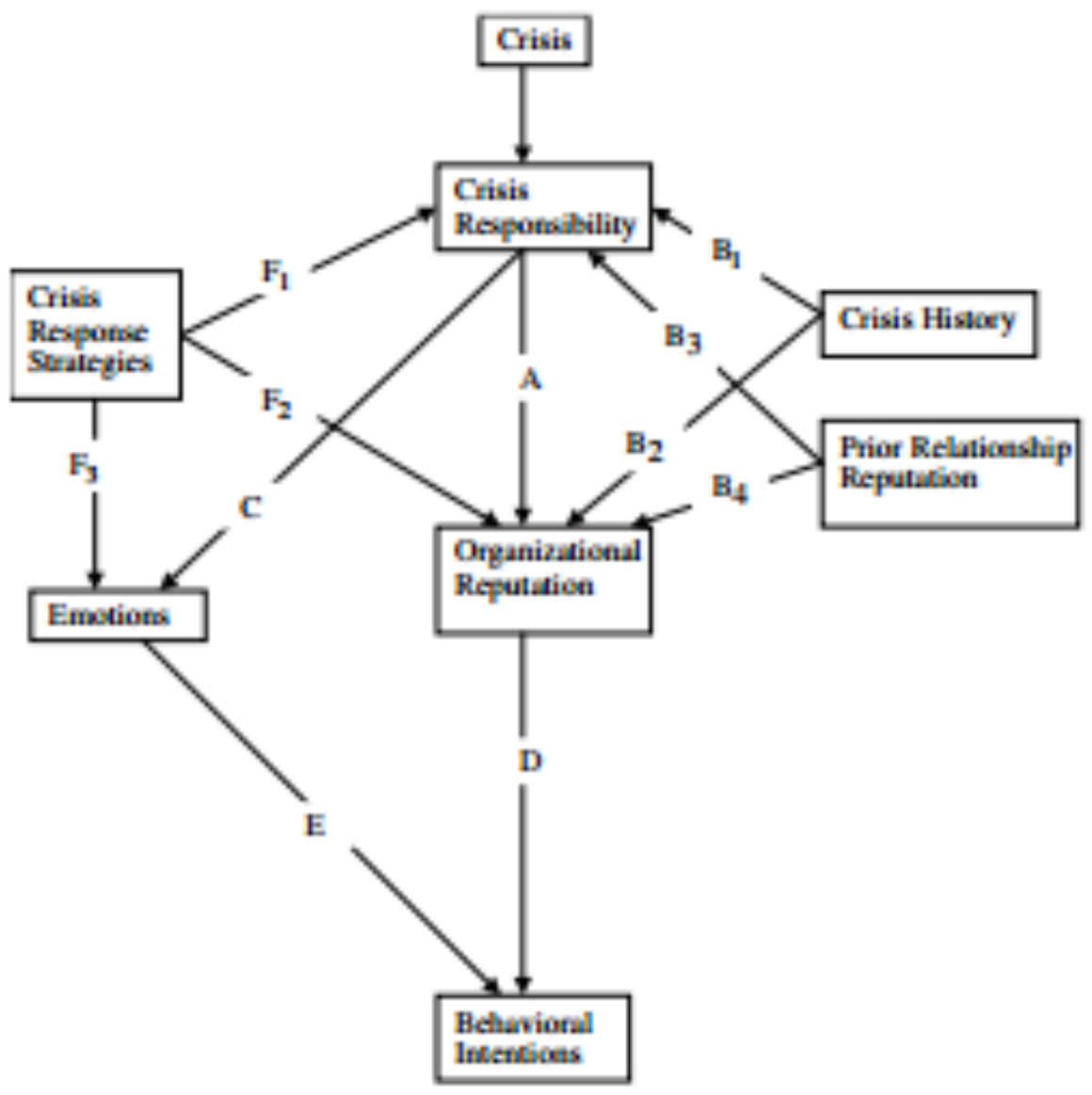


Appendix B

Twitter Demographics among internet users (2015) - PEW Research Center

\begin{tabular}{lc}
$\begin{array}{l}\text { Twitter Demographics } \\
\text { Among internet users, the \% who use Twitter } \\
\text { Internet users }\end{array}$ \\
\hline Total & $23 \%$ \\
\hline Men & 25 \\
Women & 21 \\
\hline White, Non-Hispanic & 20 \\
Black, Non-Hispanic (n=85) & 28 \\
Hispanic & 28 \\
\hline 18-29 & 32 \\
$30-49$ & 29 \\
$50-64$ & 13 \\
$65+$ & 6 \\
\hline High school grad or less & 19 \\
Some college & 23 \\
College+ & 27 \\
\hline Less than $\$ 30,000 /$ yr & 21 \\
\$30,000-\$49,999 & 19 \\
\$50,000-\$74,999 & 25 \\
\$75,000+ & 26 \\
\hline Urban & 30 \\
Suburban & 21 \\
Rural & 15 \\
\hline Source: Pew Research Center, March 17-April 12, 2015. \\
PEW RESEARCH ceNTER & \\
\hline
\end{tabular}




\section{TABLES AND FIGURES}

1. Pre-Crisis - Unmetric Data for period Mar 1, 2015 - Jul 31, 2015

\begin{tabular}{|ll|}
\hline Brand OverVIeW & \\
BRAND TWEETS & \\
Engagement Score & USER TWEETS \\
383 & Total Mention \\
& 161,901 \\
Total Proactive Tweets & Total Retweets \\
380 & 42,665 \\
& \\
Retweets Total & Total Replies \\
49 & 0 \\
Replies Total & \\
31,298 & Response Rate (\%) \\
Favorites Total & $19.4 \%$ \\
86,265 & Average Reply Time (mins) \\
\hline
\end{tabular}

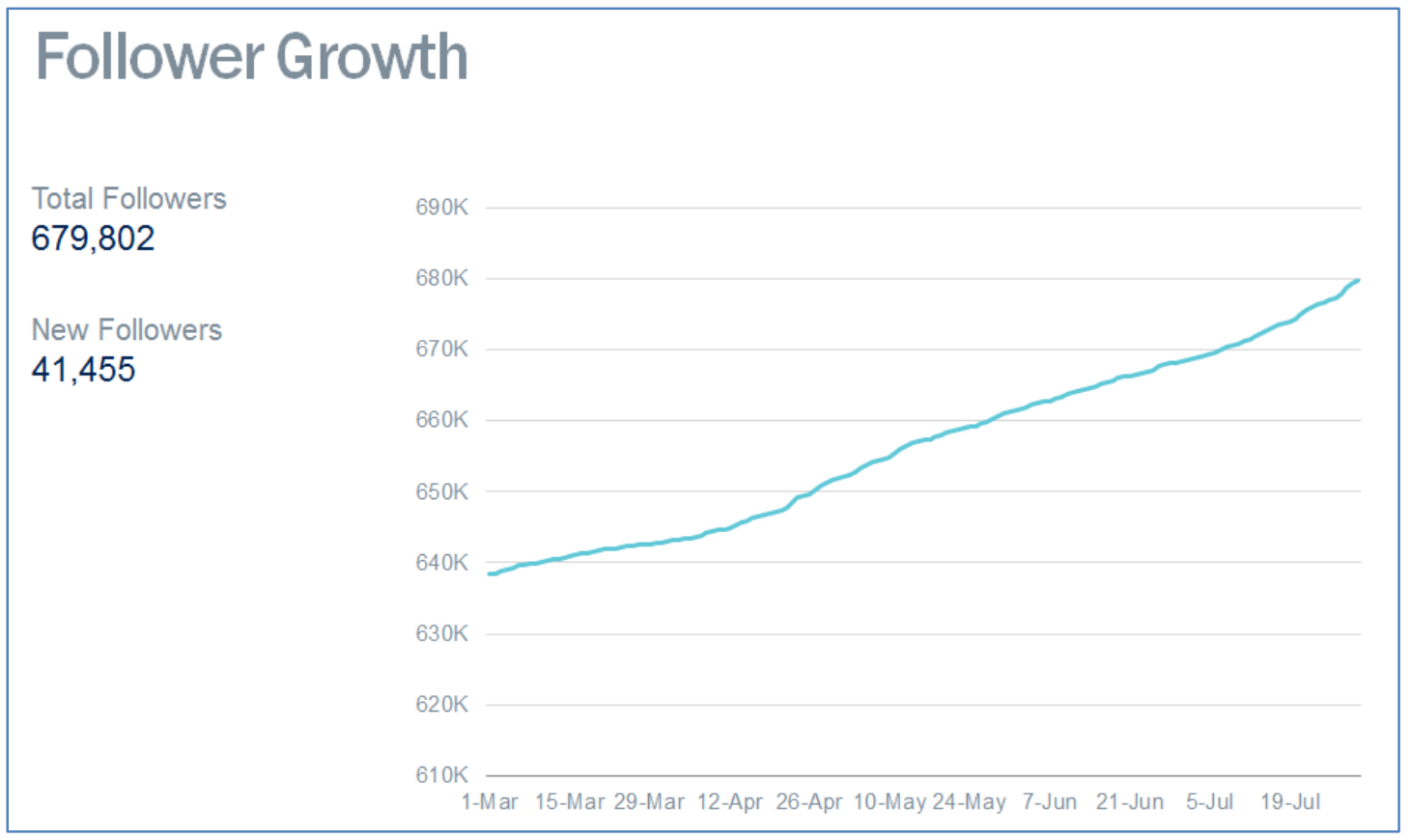




\section{Engagement}

Chipotle Mexican Grill had an average engagement score of 383 and a highest of 1,000.

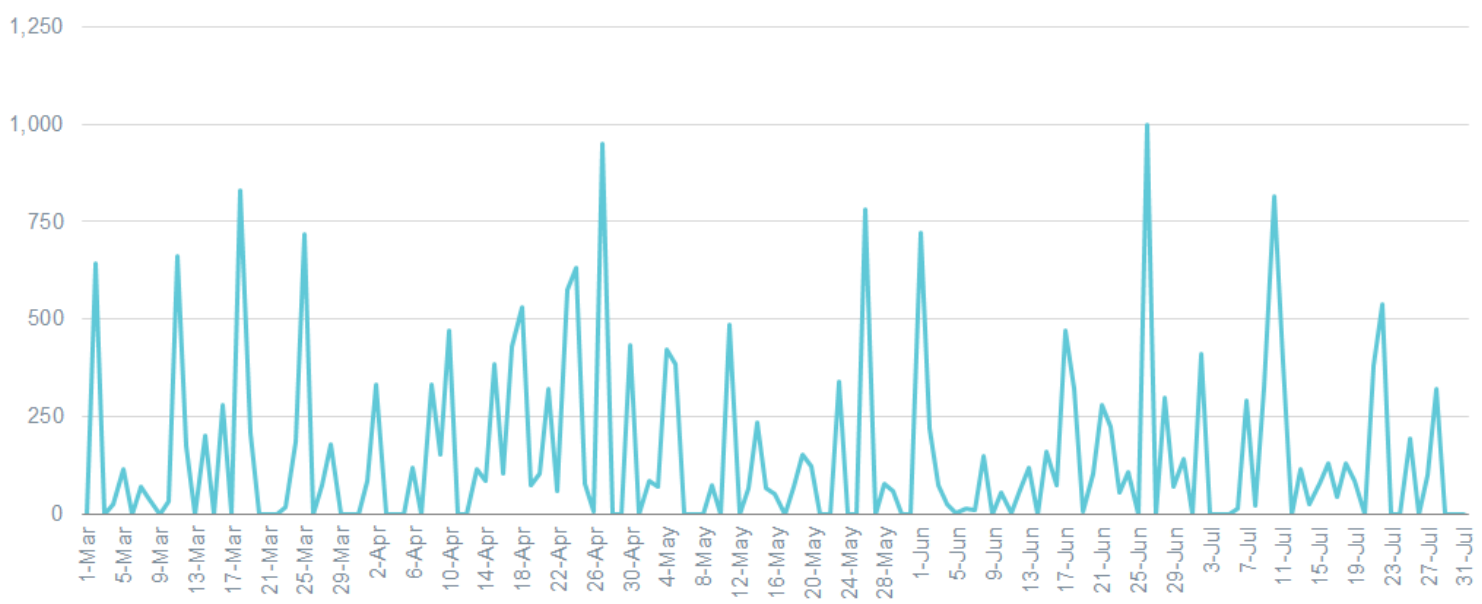

\section{Brand Tweet Types}

Posts with Hashtags engage the best. Those with Mentions are the most frequent

-Engagement Score $\quad$ Number of Tweets

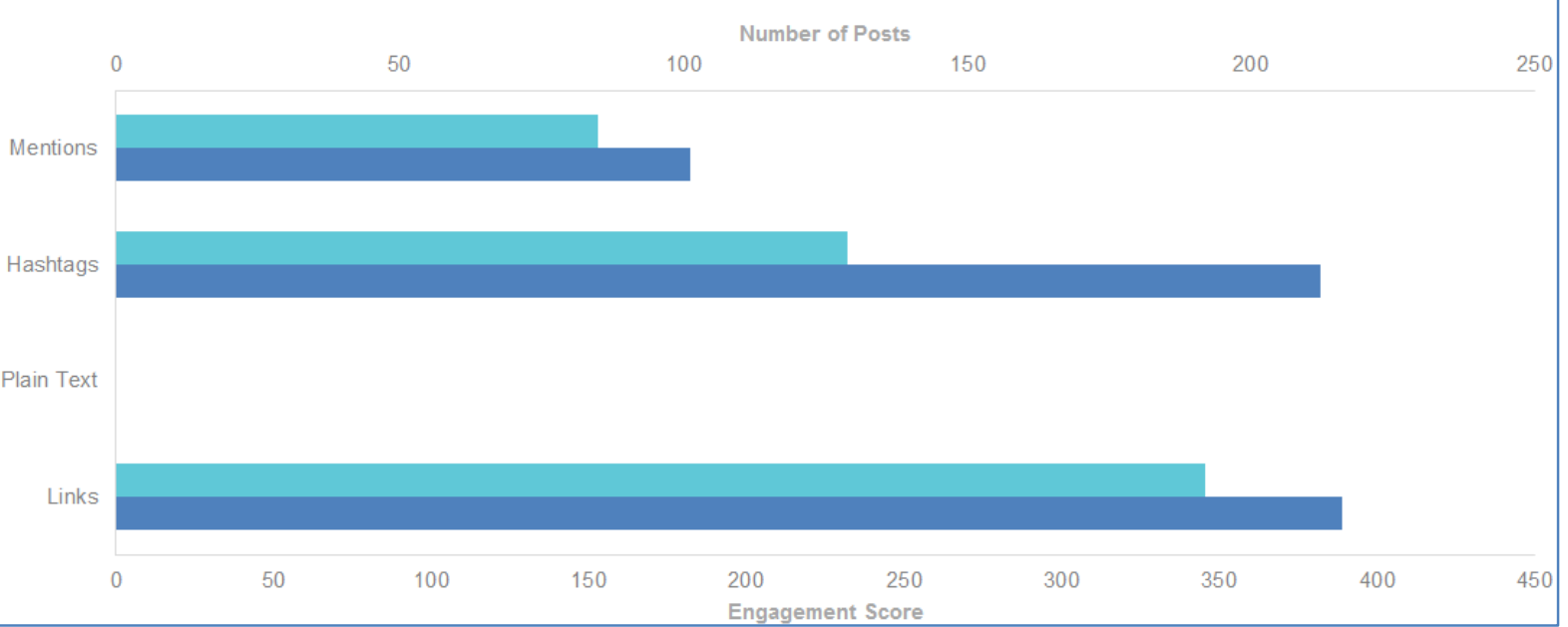




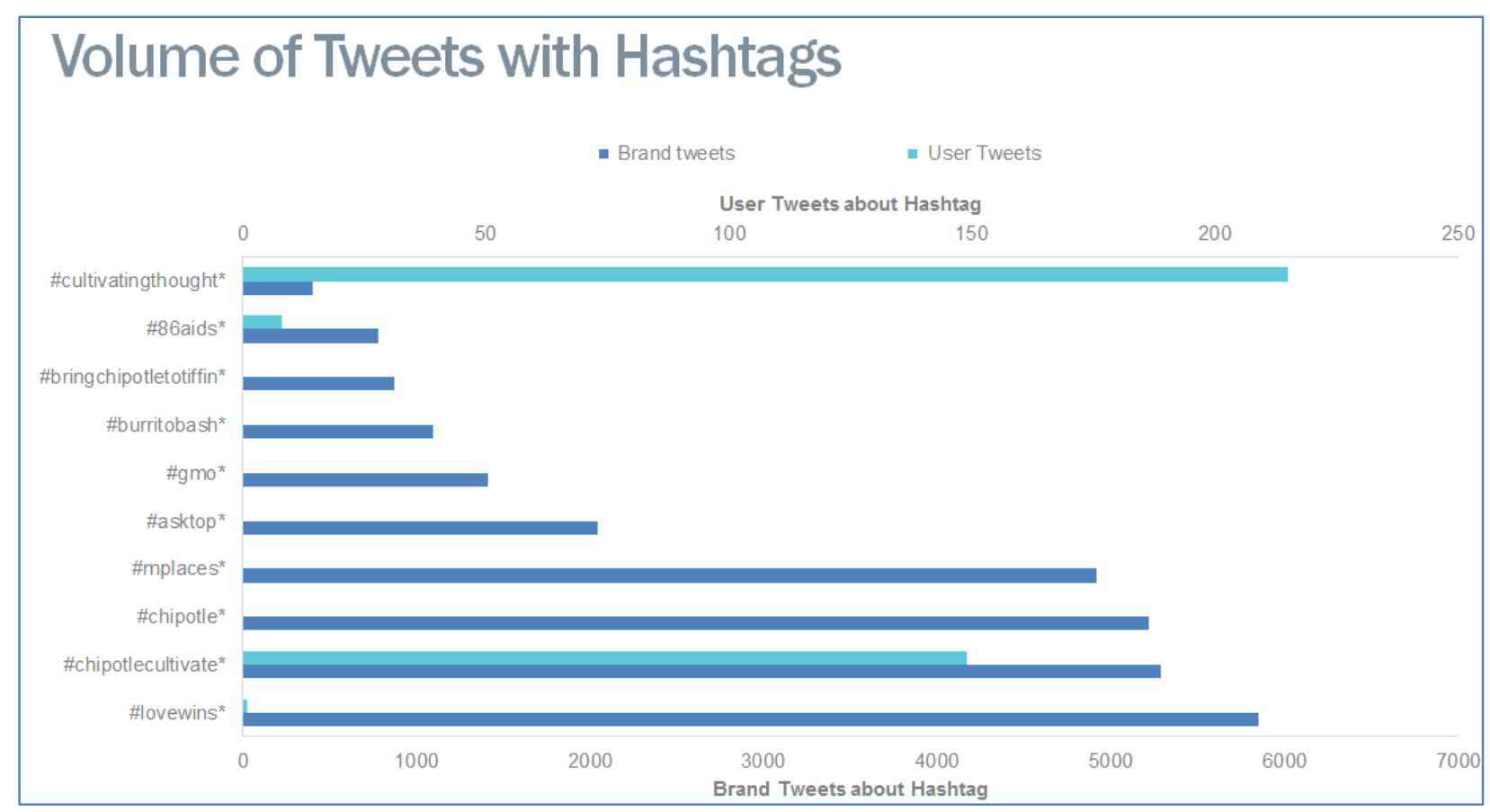

\section{Hashtags - Engagement}

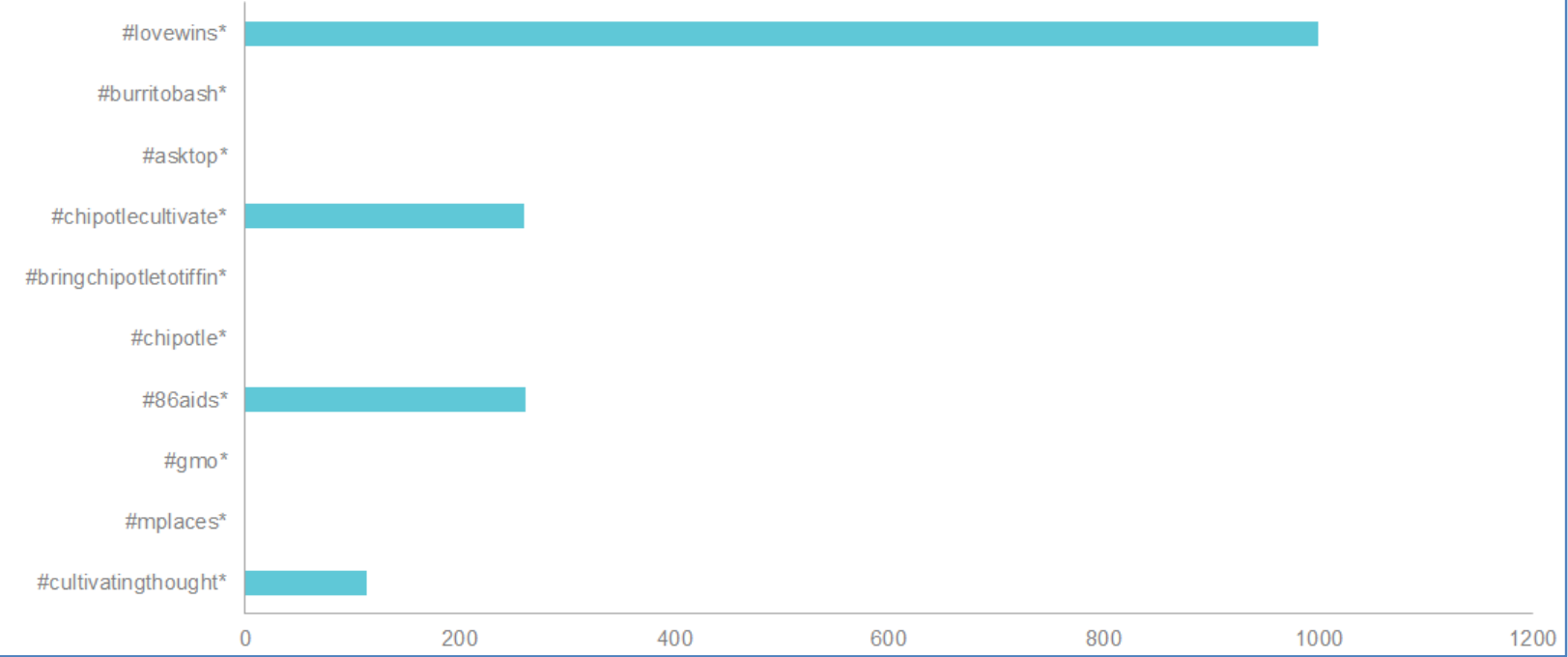




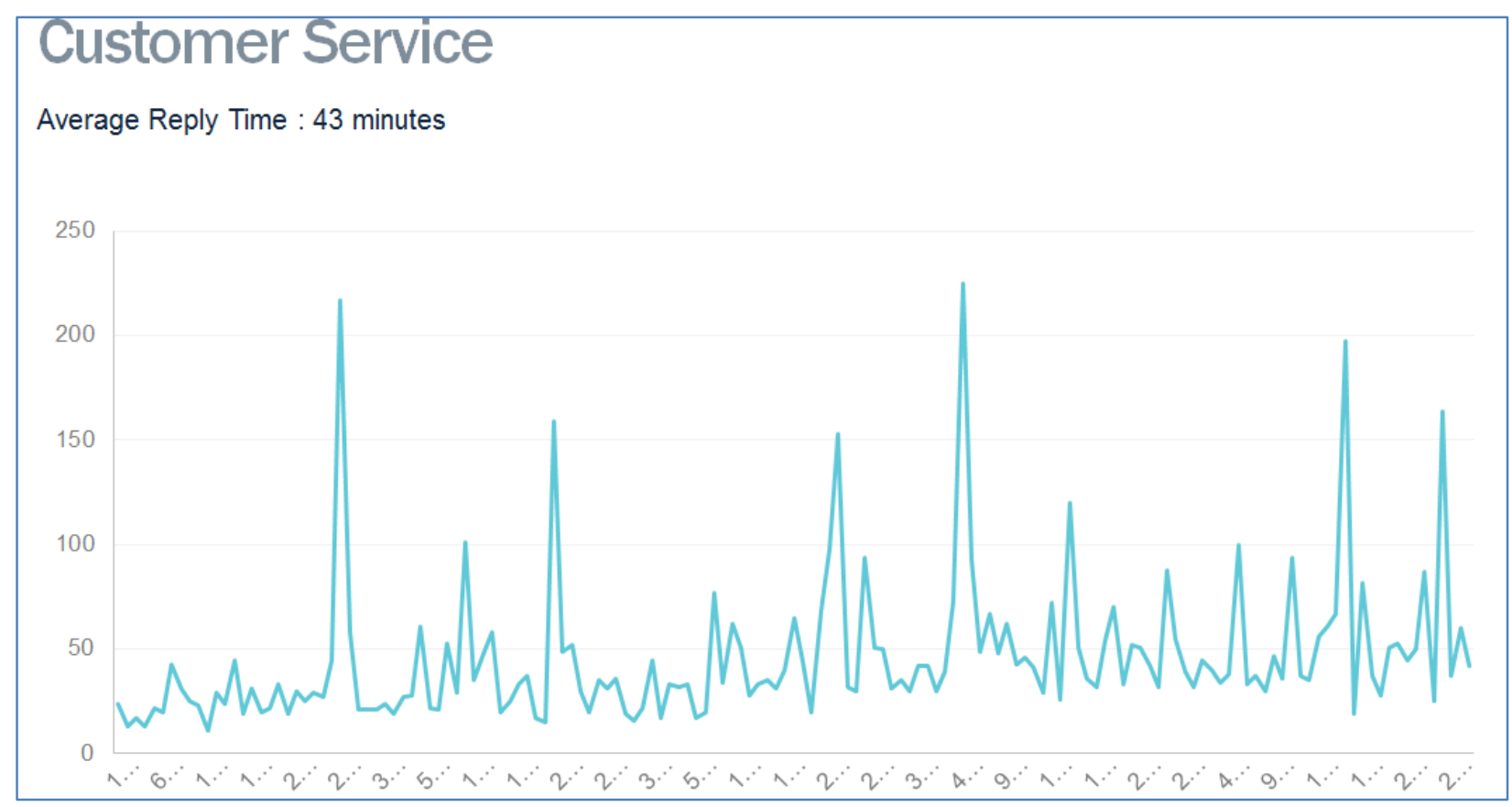

Influencers

TOP 5 INFLUENCERS

Name

Vogue Magazine

Paulo Coelho

People Magazine

Entertainment Weekly

Steve Aoki
Followers

$11,389,675$

$11,065,435$

$7,265,306$

$5,478,202$

$4,601,553$
Tweets

1

2

3

1

1 
2. During Crisis - Unmetric Data for period Oct 1, 2015 - Mar 1, 2016

\begin{tabular}{|ll|}
\hline Brand OverVieW & \\
BRAND TWEETS & USER TWEETS \\
Engagement Score & Total Mention \\
566 & 190,966 \\
& \\
Total Proactive Tweets & Total Retweets \\
741 & 108,659 \\
& \\
Retweets Total & Total Replies \\
& 0 \\
Replies Total & Response Rate (\%) \\
43,748 & $22.75 \%$ \\
Favorites Total & Average Reply Time (mins) \\
220,520 & 33 \\
& \\
\hline
\end{tabular}

\section{Follower Growth}

Total Followers

743,745

New Followers

42,091

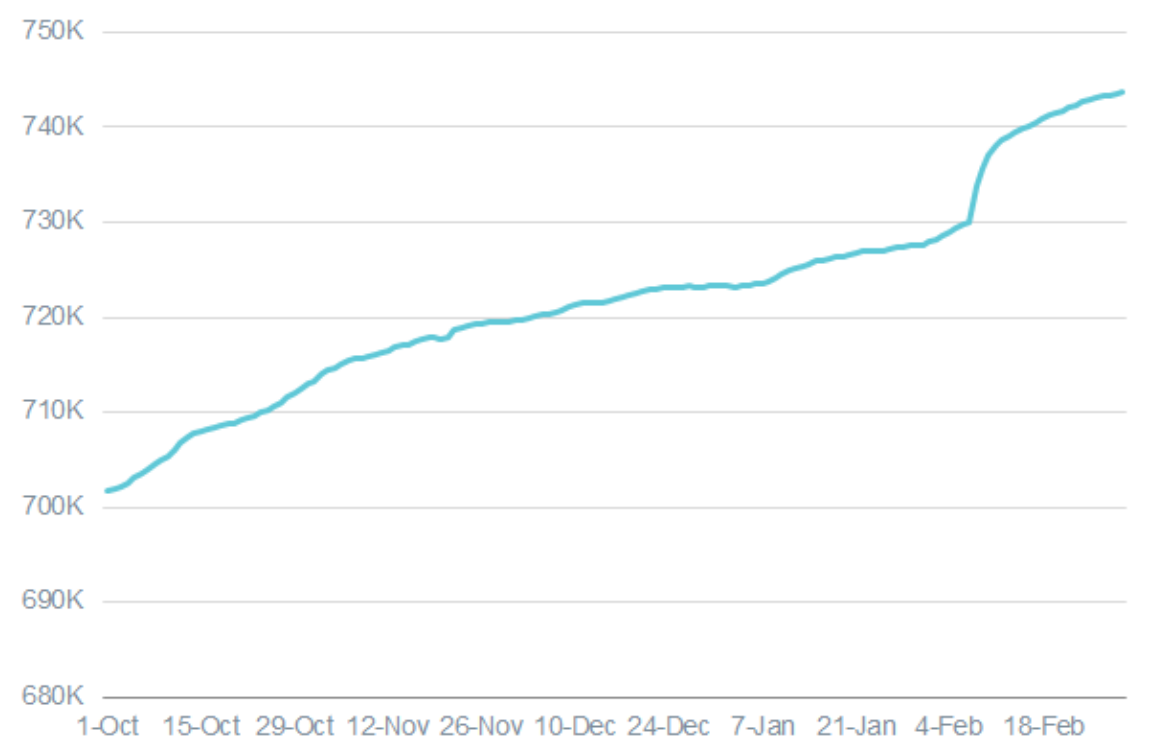




\section{Engagement}

\section{Chipotle Mexican Grill had an average engagement score of 566 and a highest of 978.}

1,250

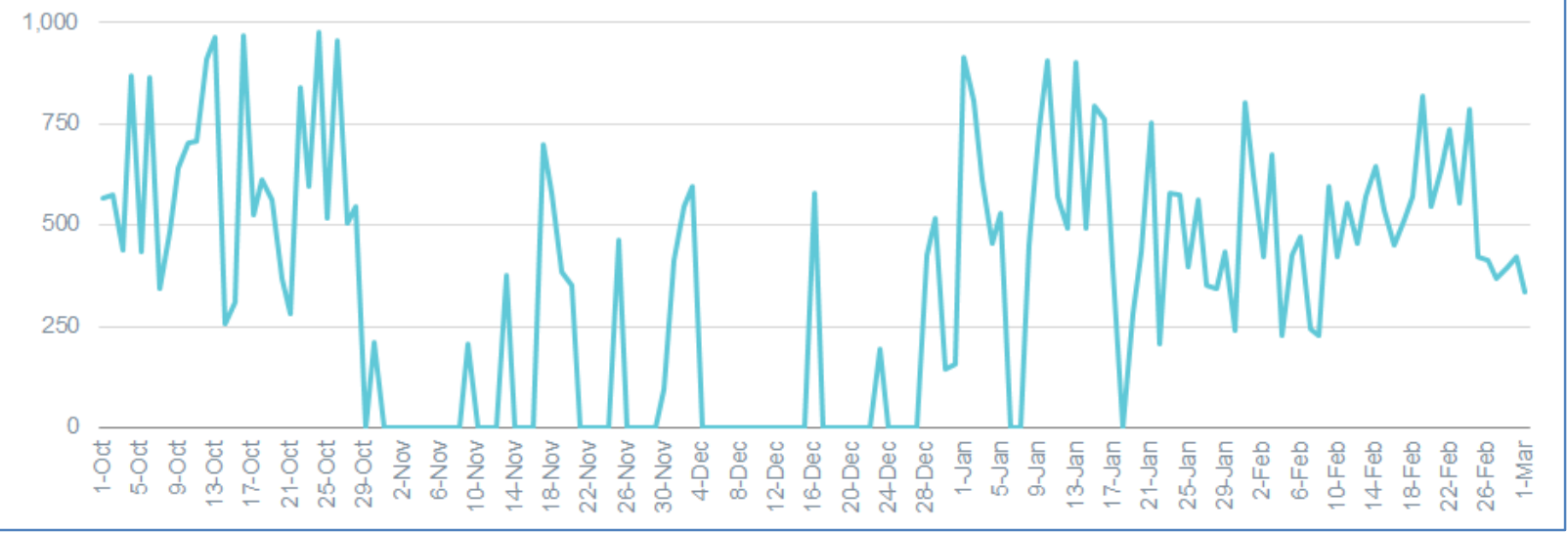

\section{Brand Tweet Types}

Posts with Hashtags engage the best. Those with Mentions are the most frequent

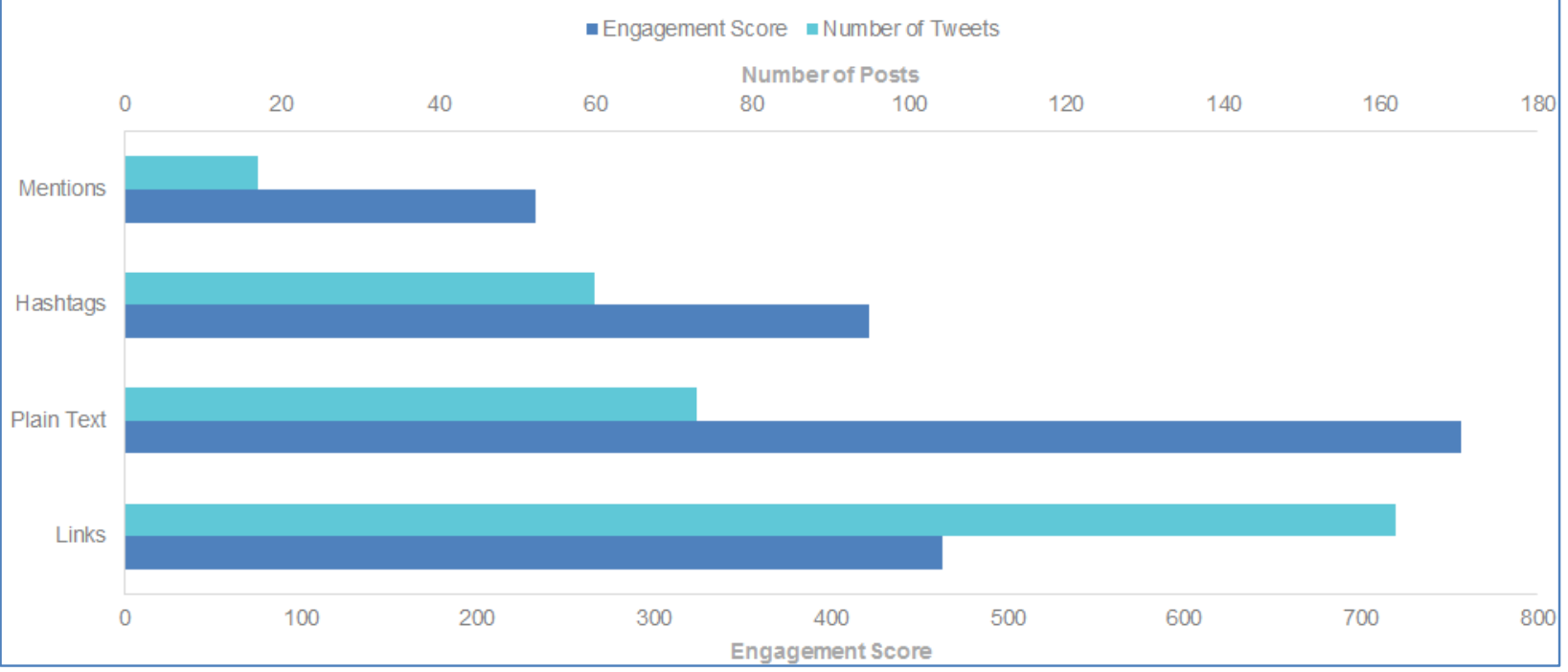




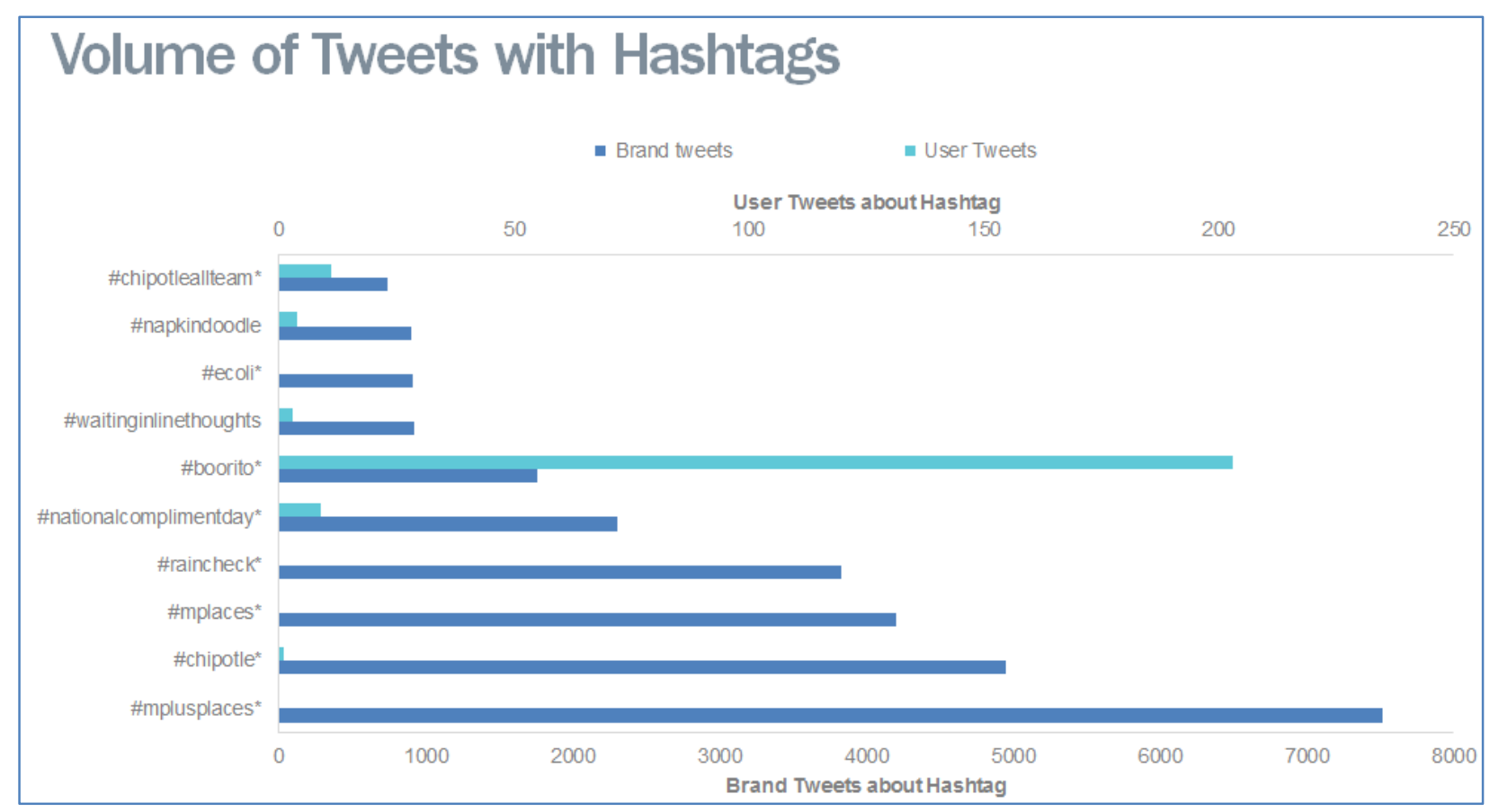

\section{Hashtags - Engagement}

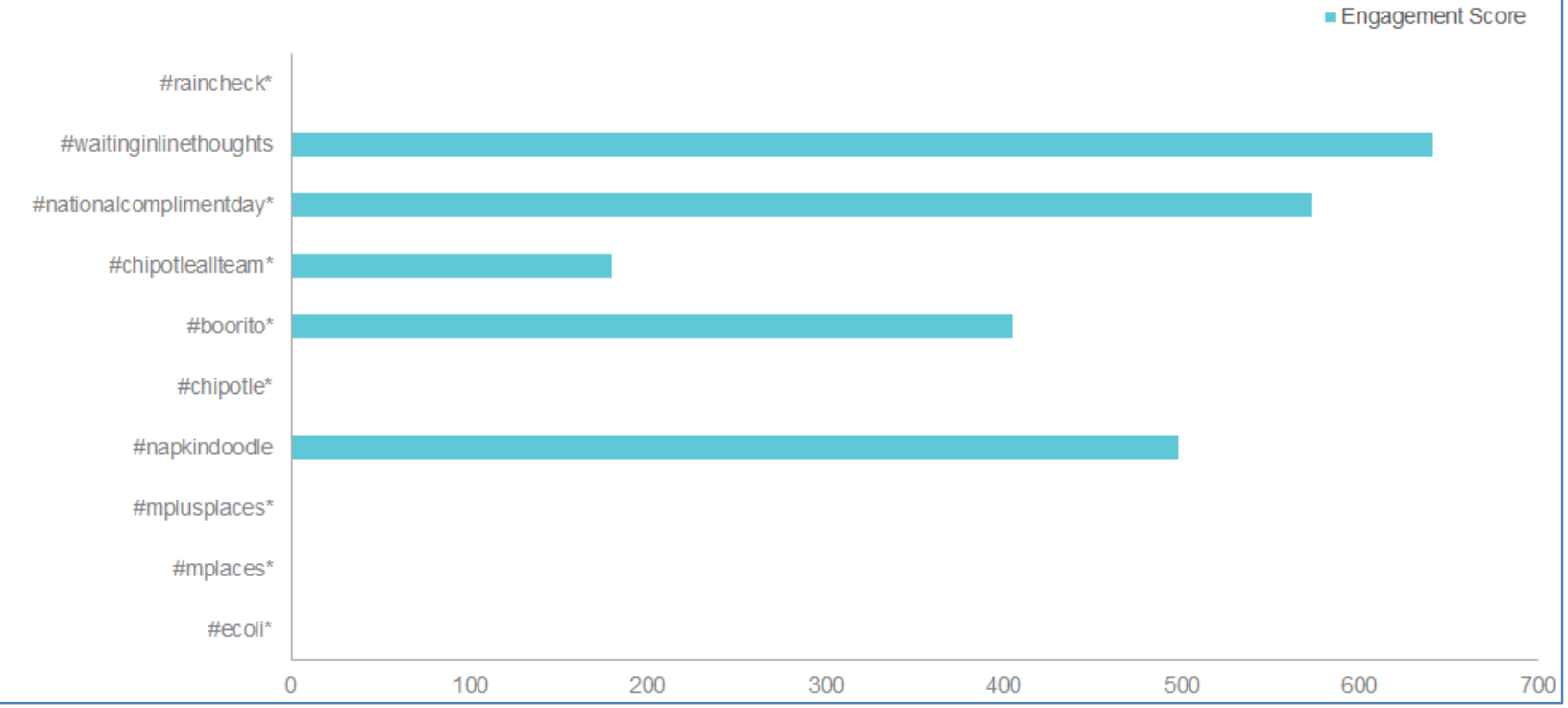




\section{Customer Service}

Average Reply Time : 33 minutes

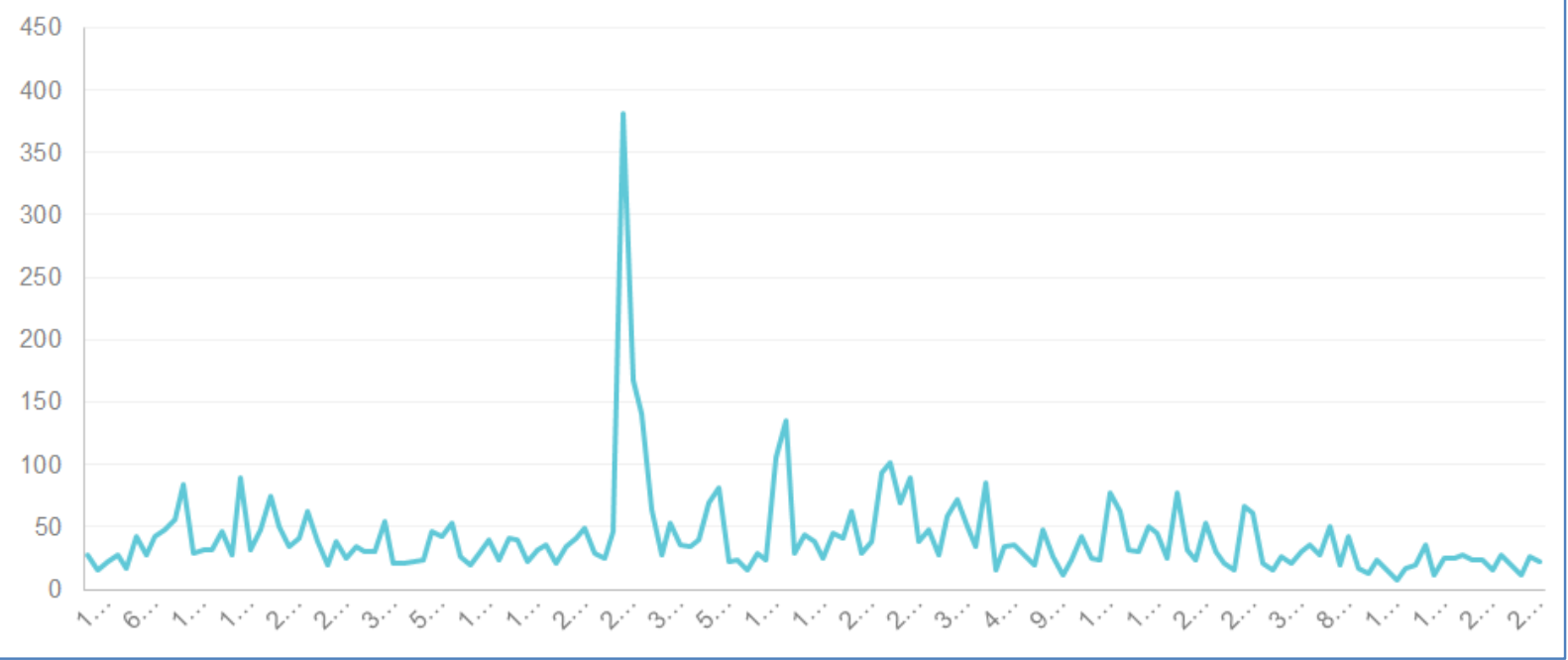

\section{Influencers}

\section{TOP 5 INFLUENCERS}

Name

Kevin Hart

CNN

Breaking News

People Magazine

debbyryan
Followers

$30,024,242$

$25,980,401$

$8,879,019$

$7,257,471$

$4,096,970$
1

1

Tweets

1

3

1 
3. Post Crisis - Unmetric Data for period April 1, 2016 - Jul 8, 2016

\begin{tabular}{ll}
\hline Brand OverVIeW & \\
BRAND TWEETS & USER TWEETS \\
Engagement Score & Total Mention \\
863 & 119,753 \\
& \\
Total Proactive Tweets & Total Retweets \\
607 & 272,114 \\
& \\
Retweets Total & Total Replies \\
2 & 0 \\
& \\
Replies Total & Response Rate (\%) \\
35,438 & $29.51 \%$ \\
& \\
Favorites Total & Average Reply Time (mins) \\
533,746 & 51
\end{tabular}

\section{Follower Growth}

Total Followers

791,287

New Followers

36,096

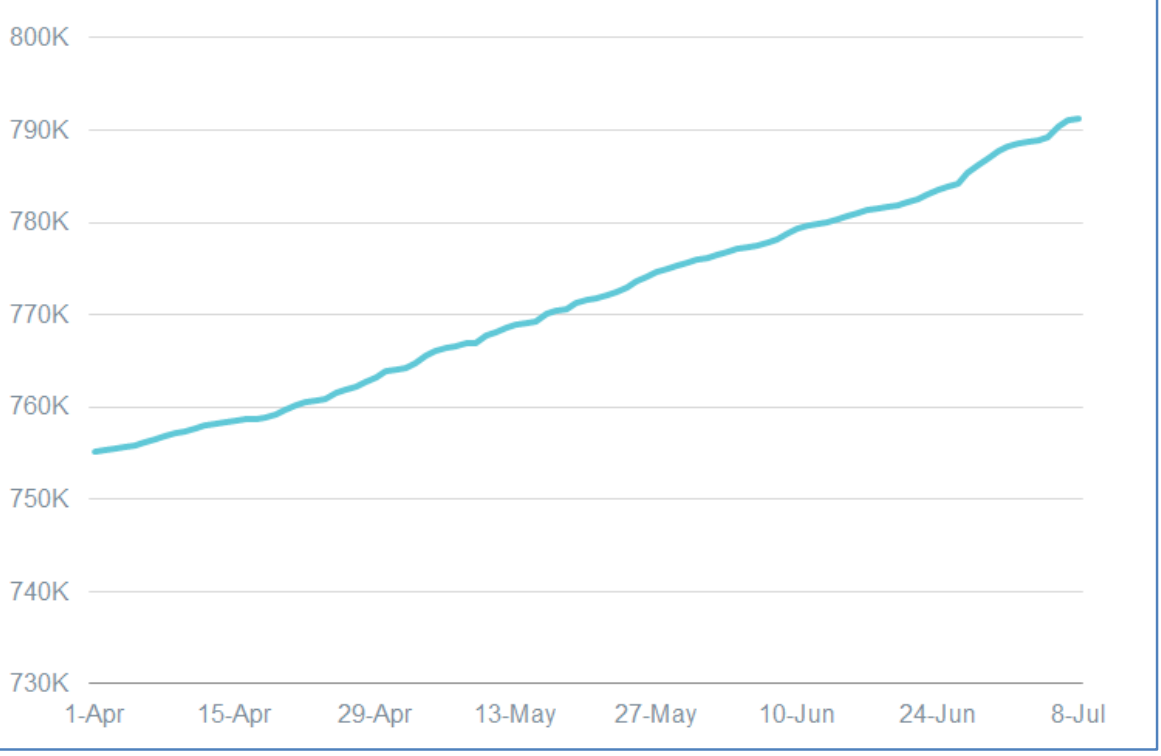




\section{Engagement}

Chipotle Mexican Grill had an average engagement score of 863 and a highest of 1,000.

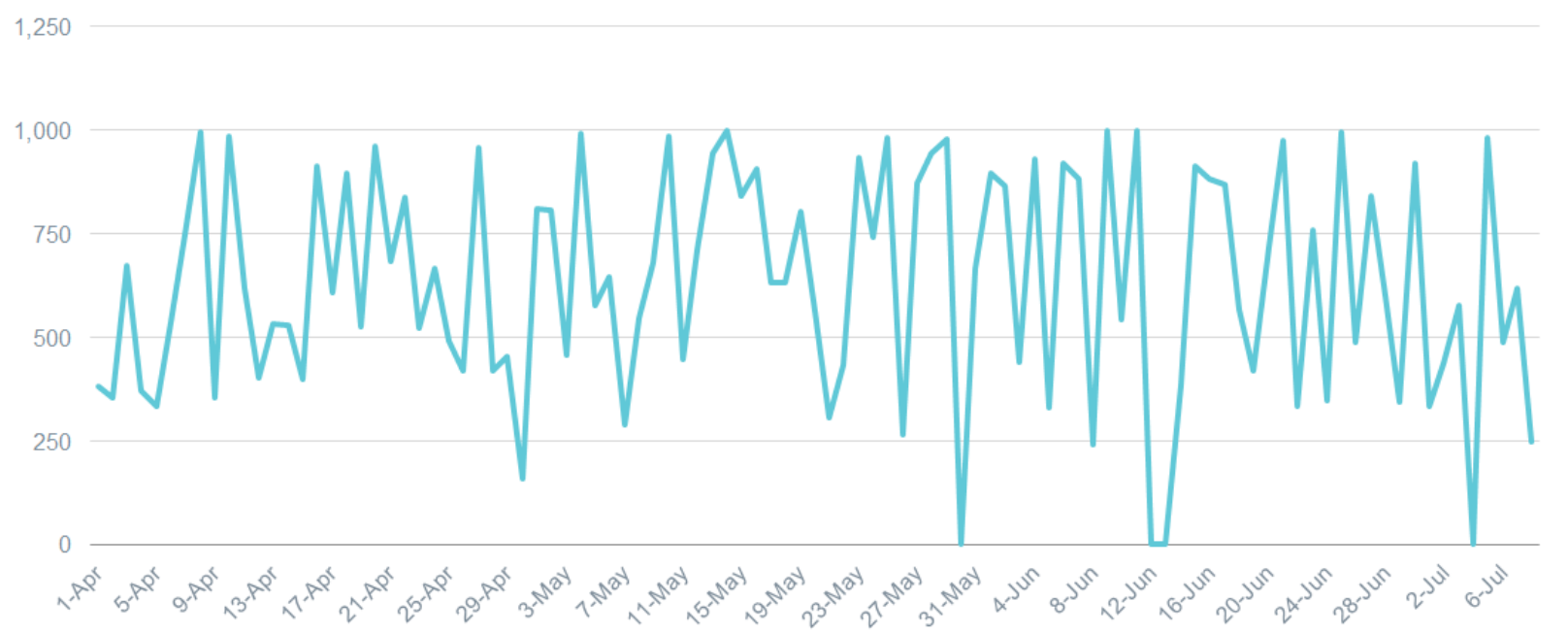

\section{Brand Tweet Types}

Posts with Hashtags engage the best. Those with Mentions are the most frequent

-Engagement Score $\quad$ Number of Tweets

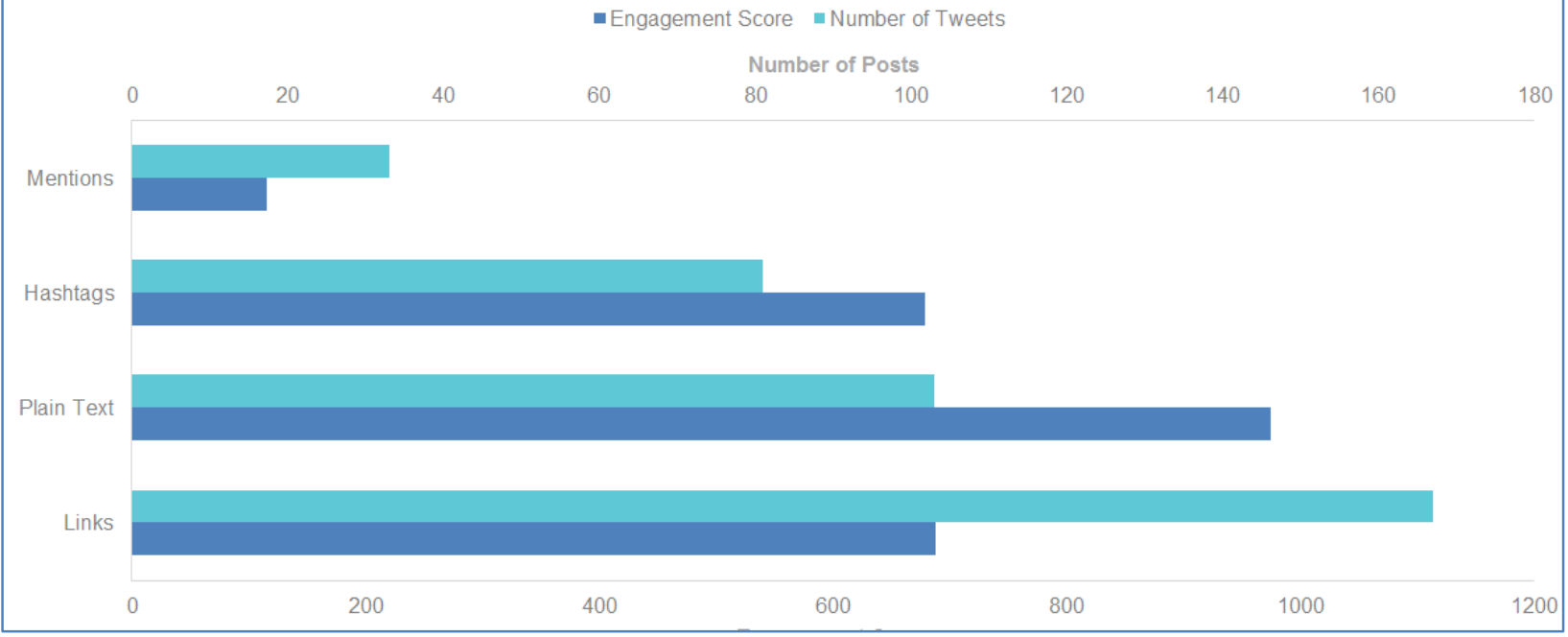




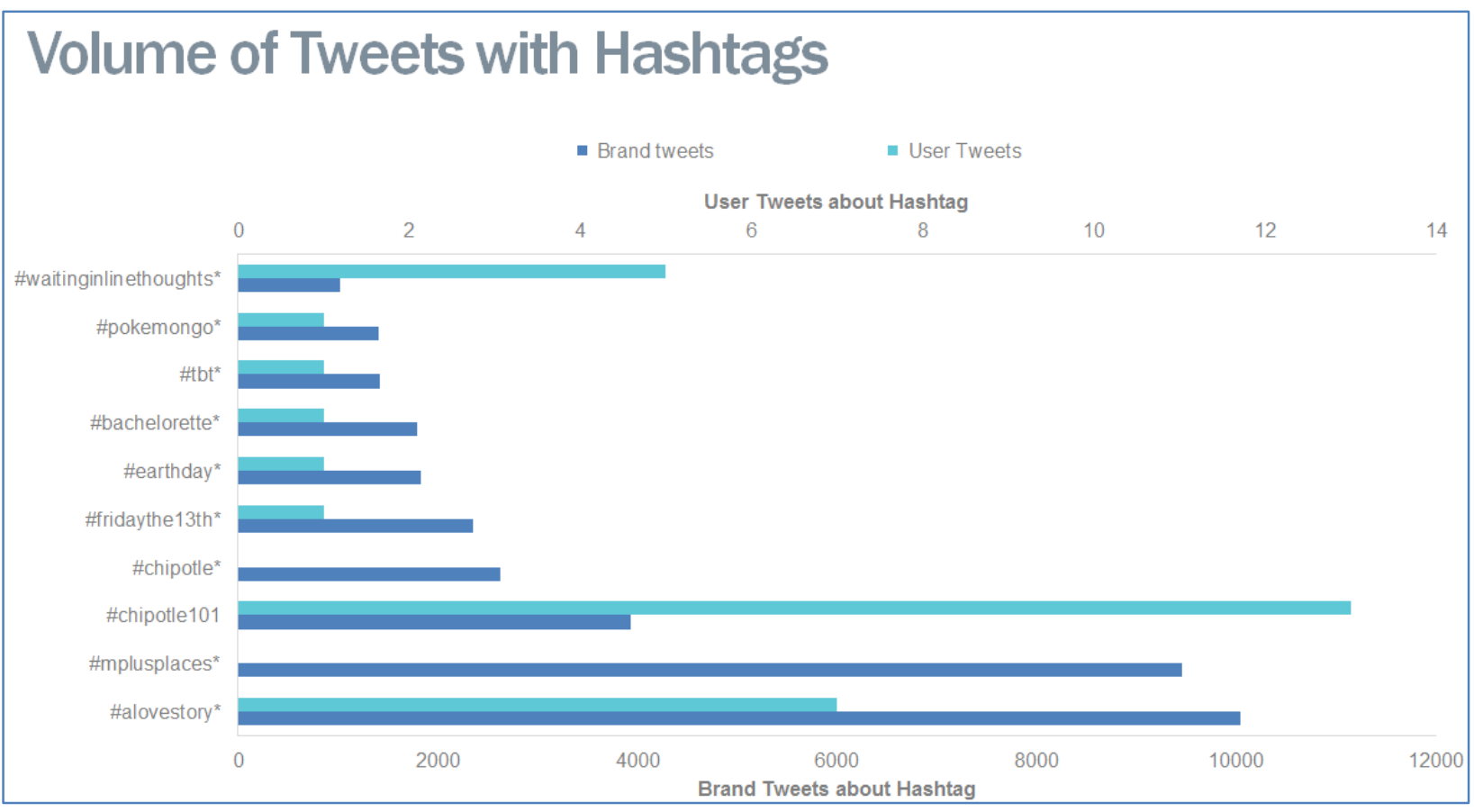

\section{Hashtags - Engagement}

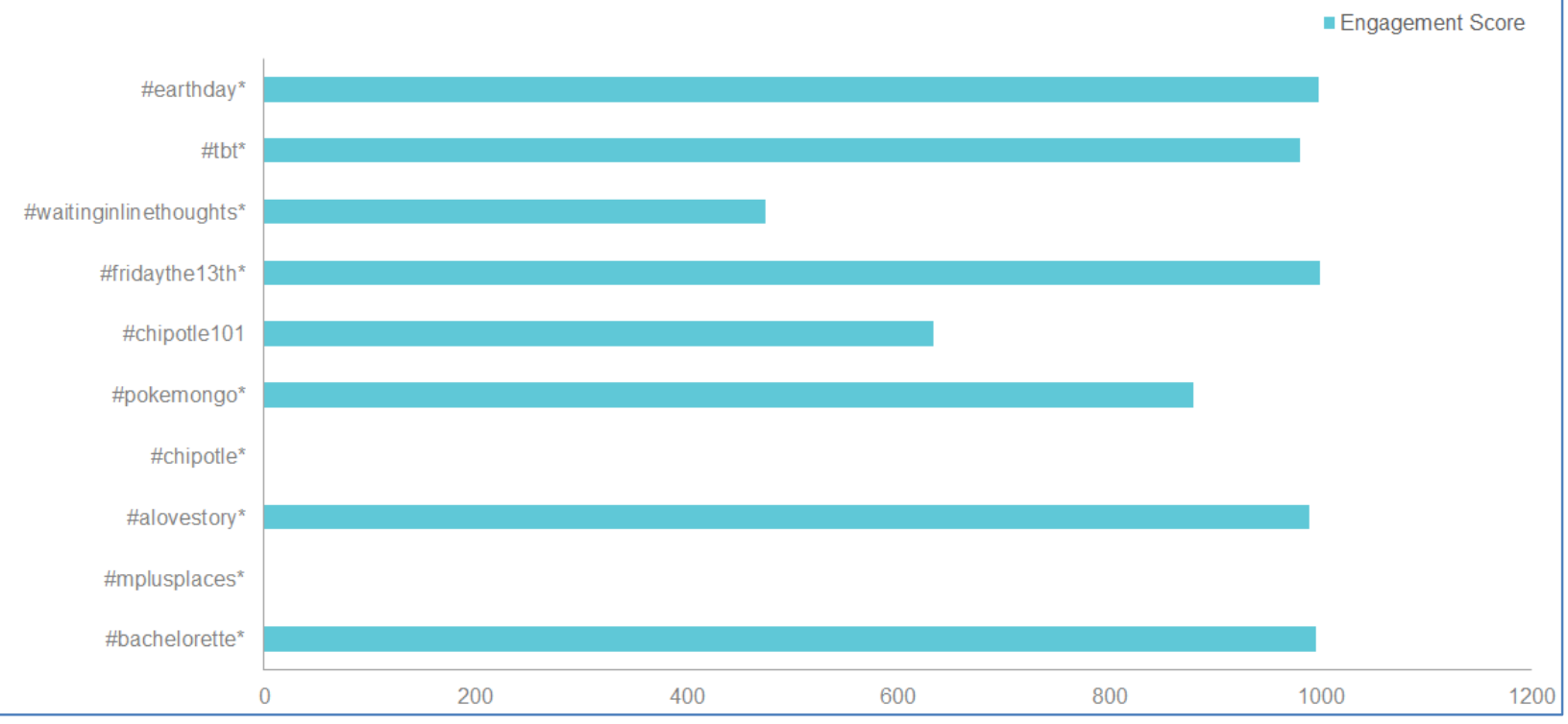




\section{Customer Service}

Average Reply Time : 51 minutes

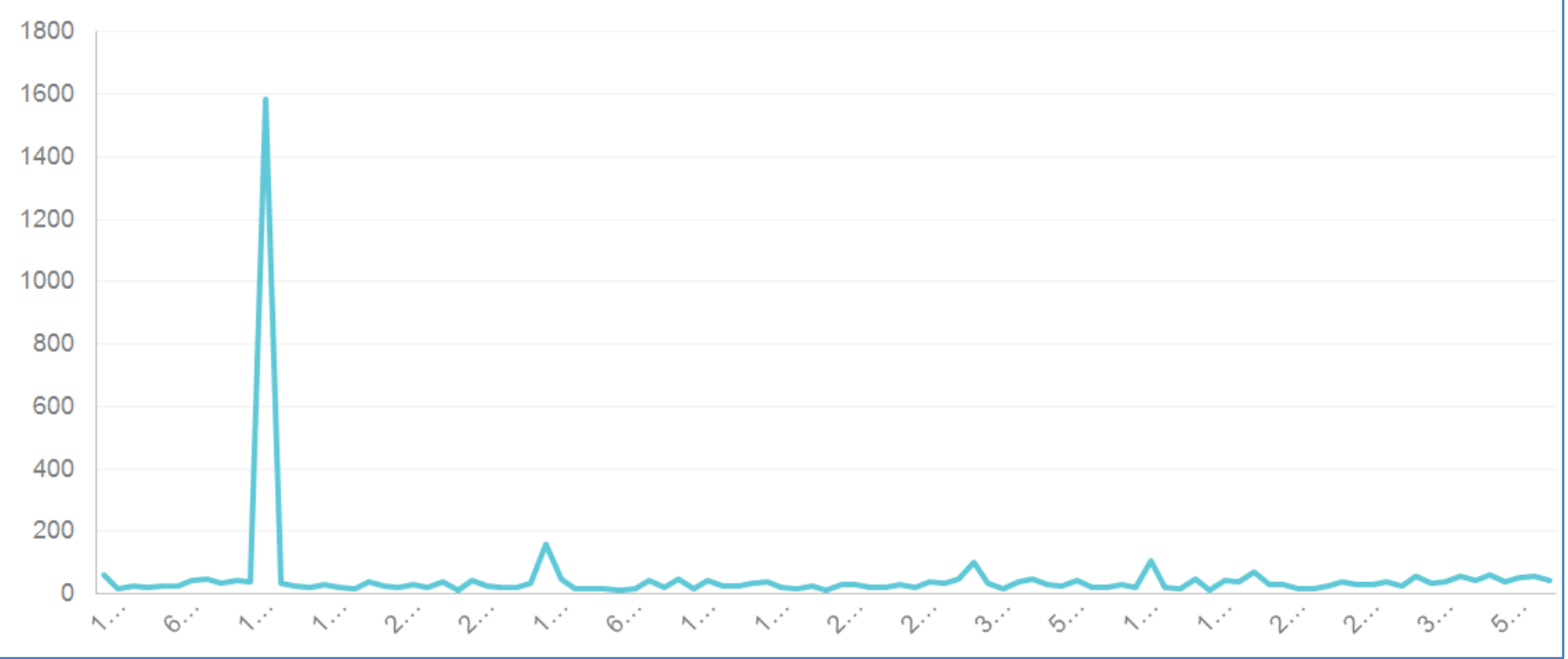

Influencers

TOP 5 INFLUENCERS

Name

Followers

June 10th

$3,760,033$

Hayes Grier

$3,501,090$

Pitchfork

$3,121,448$

Shane Dawson

$3,041,032$

Markiplier

$2,949,641$ 


\section{Reference List}

Aaker, D. A. (1996). Measuring brand equity across products and markets. California management review, 38(3), 102-120. doi: 10.2307/41165845.

Alba, D. (2016, January 15). Chipotle’s Health Crisis Shows Fresh Food Comes at a Price. Retrieved from http://www.wired.com/2016/01/chipotles-health-crisis-shows-fresh-food$\underline{\text { comes-at-a-price/ }}$

Benoit, W. L. (1995). Sears' repair of its auto service image: Image restoration discourse in the corporate sector. Communication Studies, 46(1-2), 89-105. http://dx.doi.org/10.1080/10510979509368441

Benoit, W. L. (1997). Image repair discourse and crisis communication. Public relations review, 23(2), 177-186. doi: 10.1016/S0363-8111(97)90023-0

Bernstein, M. S., Bakshy, E., Burke, M., \& Karrer, B. (2013, April). Quantifying the invisible audience in social networks. In Proceedings of the SIGCHI Conference on Human Factors in Computing Systems (pp. 21-30). ACM. doi: 10.1145/2470654.2470658

Chipotle Mexican Grill. (2016, February 2). Chipotle Mexican Grill, Inc. Announces Fourth Quarter and Full Year 2015 Results. Retrieved from $\underline{\text { http://ir.chipotle.com/phoenix.zhtml?c=194775\&p=irol-newsArticle \&ID }=2134993}$

Chipotle sued by Washington woman, Oregon man who contracted E. coli from franchise. (2015, November 9). Retrieved from http://www.nydailynews.com/news/national/lawsuit-filed$\underline{\text { chipotle-e-coli-outbreak-article-1.2427899 }}$

Consumers will punish brands that fail to respond on Twitter quickly. (2013, October 29). Retrieved from http://www.lithium.com/company/news-room/press$\underline{\text { releases/2013/consumers-will-punish-brands-that-fail-to-respond-on-twitter-quickly }}$ 
Coombs, W. T. (1995). Choosing the right words the development of guidelines for the selection of the "appropriate" crisis-response strategies. Management Communication Quarterly, 8(4), 447-476. doi: 10.1177/0893318995008004003

Coombs, W.T. (2007). Attribution theory as a guide for post-crisis communication research. Public Relations Review, 22(2), 135-139. doi: 10.1016/j.pubrev.2006.11.016

Coombs, W.T. (2007). Ongoing crisis communication: Planning, managing and responding (2nd ed.). Thousand Oaks, CA: Sage Publications.

Coombs, W. T. (2007). Protecting organization reputations during a crisis: The development and application of situational crisis communication theory. Corporate reputation review, 10(3), 163-176. doi: 10.1057/palgrave.crr.1550049

Coombs, W. T. (2014). Ongoing crisis communication: Planning, managing, and responding. Orlando, FL: Sage Publications.

Coombs, W.T., \& Holladay, S. J. (2006). Unpacking the halo effect: Reputation and crisis management. Journal of Communication Management, 10(2), 123-137. http://dx.doi.org/10.1108/13632540610664698

Coombs, W. T., \& Holladay, S. J. (Eds.). (2011). The handbook of crisis communication (Vol. 22). John Malden, MA: John Wiley \& Sons.

Dulaney, C. (2016, February 2). Chipotle, Stung by E. coli Outbreak, Posts First-Ever Sales Decline. Retrieved from http://www.wsj.com/articles/chipotle-stung-by-e-coli-outbreakposts-first-ever-sales-decline-1454449916

Elrhoul, M. (2015, July 30). Four ways brands can build customer service relationships on Twitter. Retrieved from https://blog.twitter.com/2015/research-four-ways-brands-canbuild-customer-service-relationships-on-twitter 
FDA Investigates Multistate Outbreak of E. coli O26 Infections Linked to Chipotle Mexican Grill Restaurants. (2016, February 1). Retrieved from http://www.fda.gov/Food/RecallsOutbreaksEmergencies/Outbreaks/ucm470410.htm

Friedman, L. (2016, January 26). 5 Ways Successful Brands Win With Millennials On Social Media. Retrieved from http://www.forbes.com/sites/laurenfriedman/2016/01/26/5-ways$\underline{\text { successful-brands-win-with-millennials-on-social-media/\#2ecc56ad1ae0 }}$

Freberg, K., Graham, K., McGaughey, K., \& Freberg, L. A. (2011). Who are the social media influencers? A study of public perceptions of personality. Public Relations Review, 37(1), 90-92. doi:10.1016/j.pubrev.2010.11.001

Giammona, C., \& Patton, L. (2015, December 8). Chipotle's biggest strength is suddenly its biggest weakness. Retrieved from http://www.bloomberg.com/news/articles/2015-12$\underline{08 / \text { chipotle-s-greatest-strength-is-now-its-greatest-weakness-too }}$

Gillepsie, P. (2016, February 2). Chipotle Profits Tank After E. Coli scare. Retrieved from http://money.cnn.com/2016/02/02/investing/chipotle-earnings-e-coli/index.html?iid=EL

Grossman, S. (2016, February 8). Here's how Chipotle's competitors made fun of Chipotle Today. Retrieved from http://time.com/4212691/chipotle-closed-deals-qdoba-moessouthwest/

Heath, R. L., \& O'Hair, H. D. (2009). Handbook of Risk and Crisis Communication. New York, NY: Routledge.

Hermann, C.F. (1963). Some consequences of crisis which limit the viability of organizations. Administrative Science Quarterly, (8)61-82. Retrieved from https://www.researchgate.net/profile/Todd_Laporte/publication/31318554_Working_in_ 
Practice_But_Not_In_Theory_Theoretical_Challenges_of_High-

Reliability_Organizations/links/00b7d538883ea758bb000000.pdf\#page $=216$

Hoffman, B. (2012, September 4). How 'Millennials' Are Changing Food as We Know It.

Retrieved from http://www.forbes.com/sites/bethhoffman/2012/09/04/how-millenialsare-changing-food-as-we-know-it/\#717be5da339d

How Chipotle's E. Coli Outbreak Has Brought the Chain Down to Earth. (2016, April 29). Retrieved from http://fortune.com/2016/04/29/chipotle-e-coli-earnings/

Hughes, A. L., \& Palen, L. (2009). Twitter adoption and use in mass convergence and emergency events. International Journal of Emergency Management, 6(3-4), 248-260. Doi: http://dx.doi.org/10.1504/IJEM.2009.031564

Jacobsen, J. M. H., \& Simonsen, D. M. (2011). Toward a New Understanding of Crises: Defining Organisational Crises Through a Phenomenological Approach. In Communicating Crisis in an Age of Complexity: Second International Conference on Crisis Communication at the Beginning of the 21st Century (pp. 789-805). Retrieved from http://pure.au.dk/portal/files/44786862/crisis_conference_paper_aarhus_2011.pdf

Jones, A. (2014, December 18). Who are Chipotle's Customers? Retrieved from http://marketrealist.com/2014/12/chipotles-customers/

Lundgren, R. E., \& McMakin, A. H. (2013). Risk communication: A handbook for communicating environmental, safety, and health risks. Piscataway, NJ: John Wiley \& Sons.

McLymore, A. (2016, July 22). Chipotle shares pop after missing estimate. Retrieved from http://www.cnbc.com/2016/07/22/chipotle-shares-pop-after-missing-estimates.html

Meyers, G. C., \& Holusha, J. (1986). When it hits the fan: Managing the nine crises of business. 
Boston, MA: Houghton Mifflin.

National Research Council. (1989). Improving risk communication. Washington, DC: National Academy Press.

Palen, L. (2008, November 3). Online Social Media in Crisis Events. Retrieved from https://net.educause.edu/ir/library/pdf/eqm08313.pdf

Pauchant, T. C., \& Mitroff, I. I. (1992). Transforming the crisis-prone organization: Preventing individual, organizational, and environmental tragedies. San Francisco, CA: JosseyBass.

Pearson, Christine M., and Judith A. Clair. (1998). Reframing crisis management. Academy of management review (23)59-76. doi: 10.5465/AMR.1998.192960

Pew Research Center. (2010, February ). Millennials: A Portrait of Generation Next. Retrieved from http://www.pewsocialtrends.org/files/2010/10/millennials-confident-connectedopen-to-change.pdf

Pew Research Centre. (2015, August 19). The Demographics of Social Media Users. Retrieved from http://www.pewinternet.org/2015/08/19/the-demographics-of-social-media-users/

Reese, S. D., Westphal, J. D., \& Carroll, C. E. (2004). How the mass media influence perceptions of corporate reputation: Exploring agenda-setting effects within business news coverage [Doctoral dissertation]. University of Texas, Austin, TX. Retrieved from https://www.researchgate.net/profile/Craig Carroll/publication/33983765 How the mas $\underline{\text { s media influence perceptions of corporate reputation exploring agenda- }}$ setting_effects_within_business_news_coverage_/links/0912f4ff5ffd4d4342000000.pdf

Reynolds, B., \& W. Seeger, M. (2005). Crisis and emergency risk communication as an 
integrative model. Journal of health communication, 10(1), 43-55. Doi:

http://dx.doi.org/10.1080/10810730590904571

Suh, B., Hong, L., Pirolli, P., \& Chi, E. H. (2010). Want to be retweeted? Large scale analytics on factors impacting retweet in twitter network. In Social computing (socialcom), 2010 ieee second international conference (pp. 177-184). Doi: 10.1109/SocialCom.2010.33

Taylor, K. (2016, July 7). Chipotle's stock is down after claims of food-poisoning incidents in Manhattan. Retrieved from http://www.businessinsider.com/chipotles-stock-down-afterreports-of-another-food-poisoning-2016-7

The Harris Poll Names Restaurant Brands of the Year. (2016, June 9). Retrieved from http://www.theharrispoll.com/business/Restaurant-Brands-of-the-Year.html

Top Chipotle Executive in Cocaine Bust Surrenders to New York Police. (2016, July 6). Retrieved from http://fortune.com/2016/07/06/chipotle-executive-cocaine-police/

Ulmer, R. R., Sellnow, T. L., \& Seeger, M. W. (2013). Effective crisis communication: Moving from crisis to opportunity (3ed.) Thousand Oaks, CA: Sage Publications.

Ulmer, R. R., Seeger, M. W., \& Sellnow, T. L. (2007). Post-crisis communication and renewal: Expanding the parameters of post-crisis discourse. Public Relations Review, 33(2), 130134. Doi: $10.1016 / j . p u b r e v .2006 .11 .015$

Valentini, C., \& Kruckeberg, D. (2012). New Media Versus Social Media. In: Duhé, S.”: New Media and Public Relations. New York, NY: Peter Lang.

Veil, S. R., Buehner, T., \& Palenchar, M. J. (2011). A work-in-process literature review: Incorporating social media in risk and crisis communication. Journal of contingencies and crisis management, 19(2), 110-122. doi: 10.1111/j.1468-5973.2011.00639.x

Wang, C. (2016, April 27). Shares of Chipotle slide on loss, sharp sales decline. Retrieved from 
http://www.cnbc.com/2016/04/27/shares-of-chipotle-slide-on-loss-sharp-sales-

decline.html

Wendling, C., Radisch, J., \& Jacobzone, S. (2013). The use of social media in risk and crisis communication. OECD Working Papers on Public Governance, No. 25, OECD Publishing. http://dx.doi.org/10.1787/5k3v01fskp9s-en

Weiner, B. (1972). Attribution theory, achievement motivation, and the educational process. Review of educational research, 42(2), 203-215. Retrieved from https://www.researchgate.net/profile/Bernard_Weiner/publication/270334287_Attributio n_Theory_Achievement_Motivation_and_the_Educational_Process/links/5519b8840cf24 4e9a4584b8a.pdf

Weiner, B. (1985). An attributional theory of achievement motivation and emotion. Psychological review, 92(4), 548-573.http://dx.doi.org/10.1037/0033-295X.92.4.548

Who are Chipotle's (CMG) main competitors? (2015, May 20). Retrieved from http://www.investopedia.com/ask/answers/052015/who-are-chipotles-cmg-maincompetitors.asp

Zuckerberg, M. (2015, April 25). Facebook Safety Feature. [Web log comment]. Retrieved from https://www.facebook.com/zuck/posts/10102050030813611 